\title{
Instituciones internacionales: políticas y problemas en la protección internacional de los desplazados internos colombianos
}

\section{Fernanda Queiroga Silva, Ana Paula Maielo Silva, Jeane Silva de Freitas y JosÉ KÉSSIO FLORO LEMOS*}

\section{RESUMEN}

Este artículo analiza la protección internacional de los derechos humanos, en el campo de actuación de las Instituciones Internacionales, teniendo como base un estudio de caso que objetiva identificar las políticas y los obstáculos relacionados a la protección de los desplazados internos en Colombia. De este modo, este estudio se orienta por la pregunta, a saber: ¿cuáles son las políticas y los problemas relativos a la protección internacional de los desplazados internos colombianos? Se parte de la premisa de que la ola de conflictos intraestatales, que emergió en Colombia acentuó el cuadro de complejidad y persistencia de la migración forzada, configurada, en particular, por el flujo del desplazamiento interno. En ese contexto, concluimos que la actuación de las instituciones internacionales en la protección internacional a los desplazados internos en Colombia es limitada y presenta muchas fallas, teniendo en vista que el ACNUR aún no ha logrado desarrollar una coordinación más consistente y porque las agencias humanitarias no poseen una planificación y recursos suficientes para cubrir el plan de acción para las asistencias a los desplazados internos.

\section{Palabras clave}

Colombia; desplazados internos; Derechos humanos; instituciones internacionales; Naciones Unidas.

\section{TitLE}

International institutions: policies and problems on the international protection of internally displaced Colombians

\begin{abstract}
This article analyzes the international protection of human rights, in the field of action of International Institutions, based on a case study that aims to identify policies and obstacles related to the protection of internally displaced persons in Colombia. Thus, this study is guided by the question: what are the policies and problems related to the international protection of internally displaced Colombians? The article starts from the premise that the wave of intrastate conflicts that emerged in Colombia accentuated the complexity and persistence of forced migration, shaped, in particular, by the flow of internal displacement. In this context, we conclude that the performance of international institutions in the international protection of internally displaced Colombians is limited and presents many flaws, given that UNHCR has not yet managed to develop a more consistent coordination and because humanitarian agencies do not have sufficient planning and resources to cover the action plan for assistance to internally displaced persons.
\end{abstract}

\section{KEYWORDS}

Colombia; internally displaced persons; Human rights; international institutions; United Nations.

\section{DOI:}

https://doi.org// 0.15366/relacionesinternacionales2019.40.006

\section{Formato de citación recomendado:}

QUEIROGA SILVA, Fernanda, MAIELO SILVA, Ana Paula, SILVA DE FREITAS, Jeane, y FLORO LEMOS, José Késsio, "Instituciones internacionales: políticas y problemas en la protección internacional de los desplazados internos colombianos”, en Relaciones Internacionales, n 40, 2019 , pp. 133 - 170.
*Fernanda QUEIROGA SILVA, Graduada en Relaciones Internacionales y Máster en Ciencias Jurídicas por el Programa de Posgraduación en Ciencias Jurídicas por la Universidad Federal de Paraíba - UFPB. Email: fernandaqueiroga. silva@hotmail.com

Ana Paula MAIELO SILVA, Doctora en Ciencia Política y Relaciones Internacionales por el Programa de Pos-graduación en Ciencia Política por la Universidad Estadual de CampinasUNICAMP. Email: apmaielo@gmail.com

Jeane SILVA DE FREITAS, Doctoranda en Ciencia Política por la Universidad Federal de Pernambuco UFPE. Email: jdinha. freitas@gmail.com

\section{José Késsio} FLORO LEMOS, Máster en Ciencia Política por la Universidad Federal de PernambucoUFPE (Brasil). Email: jkessiolemos@ gmailcom

Recibido:

18/09/2018

Aceptado:

26/01/2019 


\section{$\mathrm{I}$}

\section{ntroducción'}

El desplazamiento interno no es un fenómeno reciente en el sistema internacional. En realidad, los movimientos de población, tanto dentro como fuera de los estados, siempre han estado presentes en la historia de las relaciones internacionales como una constante, aunque con diversas variantes. Con el transcurso del tiempo, las motivaciones que han orientado las trayectorias de los diferentes grupos humanos, se han ido caracterizando por ser parte de un proceso que hoy se denomina como "migraciones". En este sentido, la ola de conflictos interestatales, que surge especialmente tras el fin de la Guerra Fría, han acentuado el panorama de complejidad y persistencia de la migración forzosa configurada, particularmente, por el flujo de desplazamiento interno.

De hecho, tras la Guerra Fría, los procesos de desplazamiento interno han alcanzado niveles tan alarmantes que ha recibido especial atención, tanto en el entorno político como en el académico, especialmente porque, en primer lugar, muchos estados, inmersos en conflictos armados, muestran cifras muy elevadas de desplazados. En segundo lugar, ha llamado la atención dadas las dimensiones políticas, jurídicas, económicas, psicológicas y sociales.Y finalmente, porque se trata de un fenómeno de continuidad estructural y creciente, aunque aún presenta grandes carencias en la respuesta por parte de los estados y de la comunidad internacional.

A menudo confundidos con los refugiados, los desplazados internos son personas forzadas a salir de sus casas — por conflicto armado, violencia generalizada, abusos de los derechos humanos e incluso crisis ambientales-, pero que no atraviesan una frontera internacional para garantizar su seguridad, ni son recibidos por una autoridad internacional específica, sino que por el contrario, permanecen en su país de origen bajo el amparo de su propio gobierno, incluso aunque el gobierno pueda ser la causa de su huida².

Como ciudadanos, mantienen todos sus derechos además de encontrarse bajo la protección del Derecho Internacional de los Derechos Humanos y por el Derecho Internacional Humanitario. Por este motivo, no existe un régimen, ni una agencia internacional específica dedicada a la protección de los desplazados internos en particular; lo cual dificulta la mitigación del problema y agrava los casos de violaciones de derechos humanos. Al contrario del caso de los refugiados, el desplazamiento interno tiende a ser menos visible y, por consiguiente, la sensibilización y la solidaridad internacional tienen una presencia menor. Podrá avanzarse una vez que esta temática se introduzca también en los debates al respecto que impliquen una discusión en profundidad sobre la cuestión de la seguridad internacional y los derechos humanos combinadas con las polémicas cuestiones de la soberanía estatal y la intervención humanitaria.

La responsabilidad primaria de prevenir el desplazamiento y de proteger a las Personas Desplazadas Internas (PDI) recae sobre el estado. Sin embargo, en determinadas situaciones conflicto armado, violaciones masivas de los derechos humanos, crisis ambientales - las PDI pueden encontrarse en situaciones de mayor vulnerabilidad si la autoridad estatal no ofrece soluciones duraderas a través de las políticas o normas nacionales; teniendo en cuenta que

\footnotetext{
Una pequeña versión de esta investigación fue publicada en la revista Carta Internacional, vol. I0, $\mathrm{n}^{\circ} 2$, en diciembre 20 I5. Disponible en https:// cartainternacional.abri.org.br/Carta/article/view/267. Para esta publicación, la referida investigación aún se encontraba en su estado inicial.

2 KALIN,Walter; KÜNZLI, Jörg, The law of international human rights protection, Oxford University Press, Oxford, 2009, p. 503.
} 
muchos estados están ausentes o no están preparados para hacer frente al problema, necesitando por tanto apoyo internacional.

Dentro de esta coyuntura, pocos estados son un ejemplo tan claro de esta situación como lo es Colombia. Este país vive un conflicto armado que perdura en Colombia desde hace casi cinco décadas, el cual ha contribuido en convertir al país en el estado con mayor número de desplazados del mundo. A finales del año 2017, de los 40 millones de personas desplazadas internamente en todo el mundo, cerca de 6,509 millones se encontraban en el Estado colombiano ${ }^{3}$, de acuerdo con datos presentados en el informe Tendencias Globales del ACNUR en 2018, basados en el Centro de Monitoreo del Desplazamiento Interno (IDMC, por sus siglas en inglés).A pesar de que algunas fuentes difieran sobre el número de desplazados en este lugar, existen pruebas que demuestran que se trata de un fenómeno de continuidad estructural y en aumento.

Desde el momento en que la cuestión de los desplazados internos se convirtió en una preocupación pertinente para la comunidad de estados, se sintió la necesidad, en casos como el de Colombia, de promover una cooperación internacional en el sentido de unir esfuerzos en la reducción de los efectos de esta problemática.

Las iniciativas para la construcción de una cooperación con las agencias internacionales en Colombia tuvieron lugar en el seno de la declaración de la Ley $n^{\circ} .387 / 97^{4}$ y de la elaboración de los PORDI, cuando el Estado colombiano trató, en 1997, de obtener asistencia técnica del ACNUR que ya contaba con un mandato de actuación en el territorio en favor de la protección internacional de los refugiados, desde 1996 en la atención a los desplazados internos.

Por tanto, considerando la problemática del desplazamiento interno en Colombia, teniendo en cuenta el hecho de que no siempre los estados están preparados y/o no están dispuestos a proporcionar protección a ese sector de la población; observando la realidad de que la situación de los desplazados internos es preocupante, dadas las dificultades reveladas del desplazamiento; y que vienen sucediéndose iniciativas por parte de la comunidad internacional en pro de atajar esta problemática; delimitaremos como eje central de este artículo, el análisis de la protección internacional de los derechos humanos en el campo de actuación de las Instituciones Internacionales, teniendo como objetivo principal identificar las políticas y los escollos relacionados con la protección de los desplazados internos en Colombia. De esta manera, trataremos de responder a la siguiente pregunta: ¿Cuáles son las políticas y los problemas relativos a la protección internacional de los desplazados internos colombianos?

Con tal propósito, utilizaremos un estudio de caso como técnica de análisis, con el que exploraremos el problema del desplazamiento interno en Colombia y la actuación de las organizaciones internacionales y del propio Estado colombiano ante dicha problemática.A la luz de

\footnotetext{
3 ORGANIZACIÓN DE NACIONES UNIDAS, Alto Comissariado das Nações Unidas para os Refugiados - ACNUR, Tendencias Globales: desplazamiento forzado en 2017". Disponible en https://www.acnur.org/5b2956a04.pdf (consultado el 9 de diciembre de 20I8)

4 Primera acción del estado colombiano en pro de los desplazados internos ocurrió por medio de la promulgación de la Ley $n^{\circ} 387$ del 18 de julio de 1997-por la cual se adoptaron "medidas para la prevención del desplazamiento forzado, la atención, protección, consolidación y estabilización socioeconómica de los desplazados internos por la violencia en la República de Colombia”. CONGRESO DE LA REPÚBLICA DE COLOMBIA, Ley $n^{\circ}$ 387, de 18 de julio de 1997: por la cual se adoptan medidas para la prevención del desplazamiento forzado; la atención, protección, consolidación y estabilización socioeconómica de los desplazados internos por la violencia en la República de Colombia”, I 997. Disponible en http://www.unhcr.org/refworld/docid/3dbd4c6b5.html (consultado el 25 de febrero de 20l4)
} 
las teorías institucionalistas de las Relaciones Internacionales, este artículo pretende confrontar el papel normativo de los organismos internacionales con datos empíricos de la situación colombiana. Para la recopilación de los datos utilizaremos análisis bibliográfico y documental que someterán a examen documentos e informes oficiales de las instituciones internacionales y del gobierno de Colombia, además de estudios elaborados por think tanks, periódicos de alto impacto y literatura especializada.

\section{El desplazamiento forzoso en Colombia: Contexto histórico.}

Sin duda, el alto número de personas que experimentan la problemática del desplazamiento interno ha terminado por hacer que se deba considerar la necesidad de atención de los desplazados internos con la misma o mayor preocupación que la dirigida a los refugiados ${ }^{5}$. De acuerdo con el IDMC en Colombia, a lo largo de 2017, se sumaron 6,5 millones de personas desplazadas internamente por conflicto y violencia. De estas personas, I39000 se han registrado como nuevos desplazamientos en 2017 por conflicto o violencia; y 25000 personas se refieren a aquellas que se desplazan por causa de desastres naturales, tal y como muestra el gráfico y el mapa a continuación ${ }^{6}$.

\section{Figura I - Desplazamiento interno anual por desastres y conflictos (2009-20 I7) en Colombia}

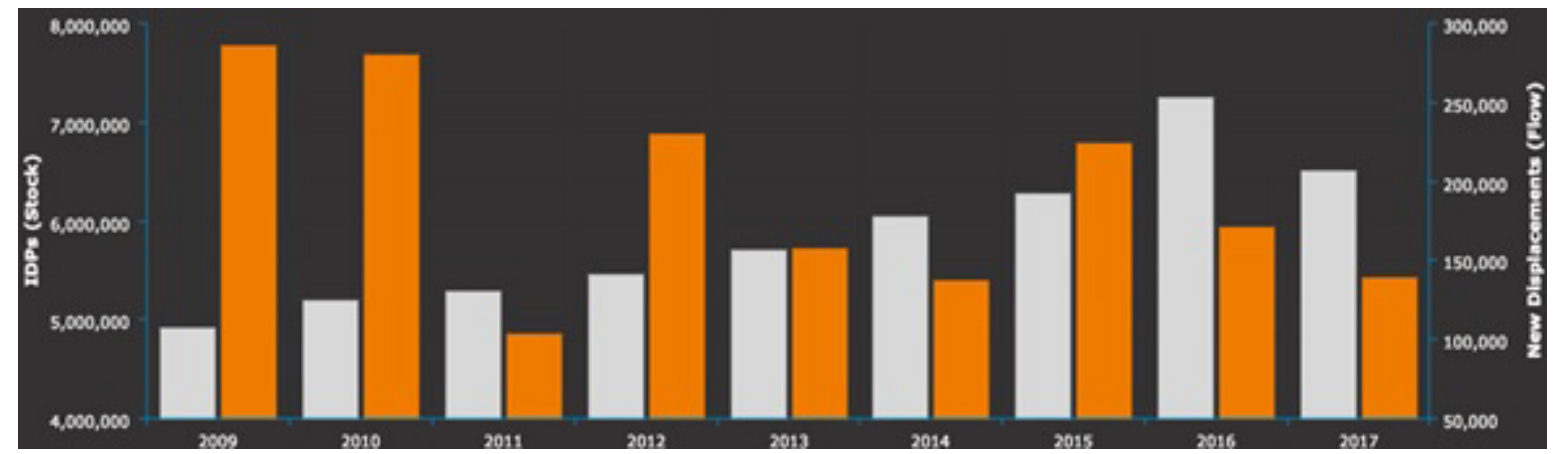

Fuente: Internal Displacement Monitoring Centre - IDMC

Así, el desplazamiento interno en Colombia ha alcanzado niveles tan preocupantes que se ha convertido en objeto de un número considerable de estudios, tanto en el entorno político como académico y, por tanto, expresamente colocado en los paneles de diversos foros de discusión que tratan la materia. El informe Tendencias Global del ACNUR de 2017 señala que, a pesar de las conversaciones de paz entre el Gobierno y las FARC que les llevaron a un acuerdo en 2016, Colombia volvió a ocupar el primer puesto en el ranking de los países con mayor número de desplazados internos, por delante de Siria, país inmerso en un contexto de guerra civil hace menos de ocho años.

COHEN, Roberta, "The Guiding Principles on Internal Displacement: a new instrument for international organizations and NGOs" en Forced Migration Review, 1998, p. 20.

6 ORGANIZACIÓN DE NACIONES UNIDAS,Alto Comissariado das Nações Unidas para os Refugiados - ACNUR, Tendencias...op. cit., p. 2.

7 INTERNAL DISPLACEMENT MONITORING CENTRE - IDMC, Global Reporto n Internal Displacement (GRID 2018). Conflict displacement Figures analysis. Disponible en http://www.internal-displacement.org/sites/default/files/20I8-05/GRID\%202018\%20-\%20Figure\%20Analysis\%20 -\%20COLOMBIA.pdf (consultado el 08 de diciembre de 2013) 
Figura 2 - Principales eventos de desplazamiento interno en Colombia en 2017

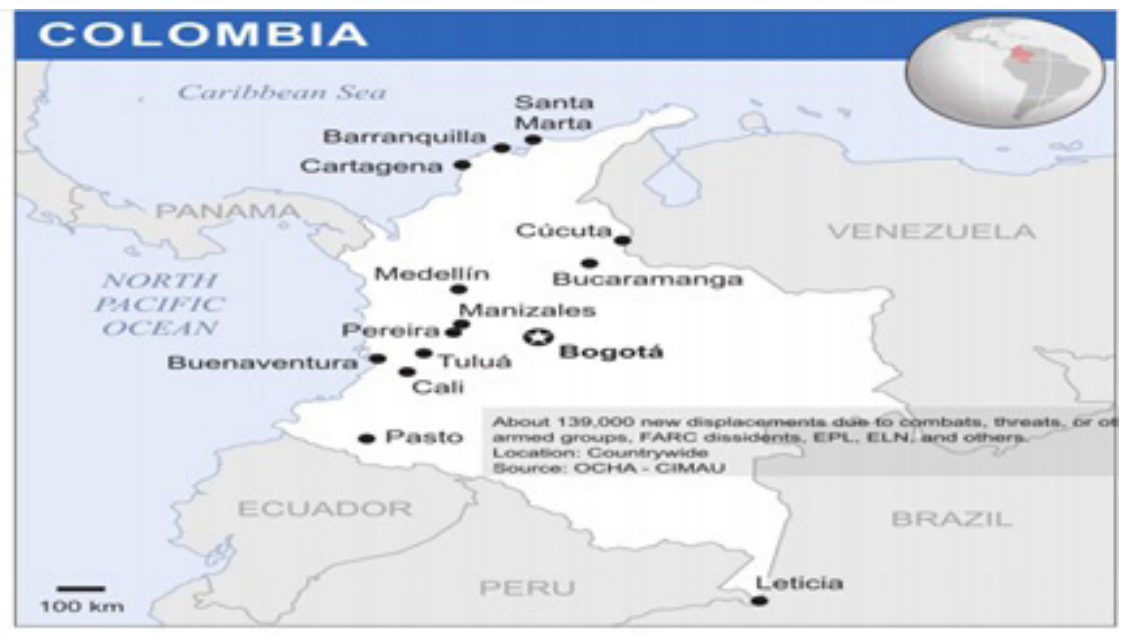

Fuente: Internal Displacement Monitoring Centre - IDMC ${ }^{8}$

En esta ocasión, el fenómeno de la migración forzada nos remonta a la configuración del Estado colombiano bajo una óptica diversificada, llena de significados e implicaciones. Dentro del contexto que se presenta en Colombia es fundamental que se considere la tensión entre los niveles de acción internacional, nacional y local ${ }^{9}$. Es necesario tener en cuenta el conflictivo papel del estado y de las políticas sociales en relación a los procesos de distribución de la población en el espacio territorial, así como los compromisos internacionales asumidos a favor de la ampliación y puesta en marcha de los derechos humanos de los migrantes ${ }^{10}$.

Existen diversas causas para el desplazamiento en Colombia. Para Viana'", la violencia propagada por el conflicto armado ha provocado un proceso paralelo de desenraizamiento interno. Sin embargo, el desencadenamiento de los desplazamientos ya se podía observar desde el periodo de independencia del estado, cuando las disputas por el poder entre los dos partidos tradicionales colombianos —el partido conservador y el liberal-entre 1830 y 1958, así como por la lucha por la posesión de las tierras, se intensificaran y generaran una ola de violencia.Además, la formación geográfica poco integradora del Estado colombiano y sus consecuentes divergencias regionales contribuyeron para que el estado permaneciese carente de un ideario nacional común, haciendo prevalecer las disparidades regionales y partidarias de las élites políticas y económicas; las cuales pasaron a resolver sus conflictos por medio de la violencia con ejércitos propios. A lo largo del tiempo, los conflictos entre liberales y conservadores se cruzaron con las revueltas

8 INTERNAL DISPLACEMENT MONITORING CENTRE - IDMC, Global IDP estimates (1990-20II), 20II. Disponible en http://www. internaldisplacement.org/8025708F004CE90B/(httpPages)/I0C43F54DA2C34A7CI2573A 1004EF9FF?OpenDocument (consultado el I3 de Noviembre de 2013)

9 Según Mazón en el actual contexto de orden y gobernanza mundiales se destacan dos nuevas formas de inseguridad global: la violencia y las débiles estructuras estatales, que resultan en la complicada interacción entre la seguridad nacional e internacional.Ver MAZÓN,Ann,"La crisis de seguridad en Colombia: causas y consecuencias internacionales de un estado en vía de fracas" en Revista Colombia Internacional, $n^{\circ}$ 49-50, 2000, pp. 82-102.

10 PATARRA, Neide Lopes. "Migrações Internacionais: teorias, políticas e movimentos sociais" en Estudos Avançados, vol. 20, n 57, 2006, ps 0708.

" VIANA, Manuela Trindade, "Cooperação internacional e deslocamento interno na Colômbia: desafios à maior crise humanitária da América do Sul” en Revista Internacional de Direitos Humanos - SUR, San Paulo, vol. 6, n 10, 2009, p. 139. 
protagonizadas por la clase popular y media, haciendo surgir incontables guerras civiles ${ }^{12}$.

El conflicto colombiano presenta motivaciones complejas que se manifiestan a lo largo de todo el territorio. Sin embargo, algunos autores consideran cuatro variables que condicionaron el desplazamiento interno en Colombia:"conflicto armado; disputa por los territorios con valor geoestratégico; disputa por la tierra, en un proceso de reordenamiento artificial; $y$ motivaciones sociales"' 3 . A pesar de que no hay un consenso entre los expertos sobre las causas del conflicto, existe un punto de encuentro entre los estudios que es, sin duda, la disputa territorial. Otro factor que debe ser destacado es la debilidad institucional del estado, como factor polarizador de políticas y desigualdades socioeconómicas frente a un orden social capitalista, lo cual posibilita el surgimiento de grupos insurgentes en la mitad del siglo $X X^{14}$.

Dicho contexto puede explicarse en tres periodos históricos, lo que implica: diferentes actores, contexto geográfico e intensidad del conflicto. Una primera fase se ubica entre los años 1920 y 1960, periodo en el cual se definieron los principales elementos de la política y del conflicto en Colombia; sobre todo en la herencia de las expresiones violentas traídas de conflictos anteriores ${ }^{15}$. Esta primera fase se vio influida por las disputas territoriales en las que el desarrollo del capitalismo y el proceso de urbanización en la región ocasionaron muchos conflictos sociales involucrando así a pueblos indígenas, campesinos y trabajadores ${ }^{16}$. La principal característica de dicho periodo fue la política bipartidista violenta observada en varios momentos, tales como: la república liberal (1930-1946); la persecución de los conservadores (1930-1938); el periodo de la "violencia"|17 (1948-1958); el estado de sitio y la dictadura del general Rojas Pinilla (1946-1958); la muerte del candidato a la presidencia por el partido liberal, Jorge Eliecer Gaitán, seguida de la eliminación de su partido $\left(\right.$ I948-1953) ${ }^{18}$.

La segunda fase se sucede entre los años de 1958-1962 a 1989-1991. Para numerosos autores, este periodo marcó el inicio de lo que hoy conocemos del conflicto armado en Colombia, especialmente con el fin del Frente Nacional, extendiéndose hasta el inicio de los años ochenta con el aumento del narcotráfico. A pesar de estos factores, los especialistas coinciden en que la cuestión de la distribución de la tierra ha sido la principal problemática del conflicto colombiano hasta día de hoy ${ }^{19}$.

La tercera fase se encuentra entre la última década del siglo XX hasta la fecha (I990-20I6).

\footnotetext{
12 SANTOS, Marcelo, "O conflito colombiano e o Plano Colômbia” en UFRR (Coleção Relações Internacionais), vol. 3, 20II, pp. 17 y 20.

13 VIANA, Manuela Trindade, “Cooperação internacional e deslocamento interno...op. cit., p. 140.

14 DUQUE, Karol Vanessa Ramirez, "Análise espacial do deslocamento forçado na Colômbia por causa do conflito armado interno", Dissertação (Mestrado em Geografia Humana) - Universidade de São Paulo, San Paulo, 2017. Disponible en http://www.teses.usp.br/teses/ disponiveis/8/8I36/tde-07022018-10324I/es.php (consultado el 21 de Febrero de 2019), p. 16.

${ }_{15}$ MOLINA, G., Las ideas socialistas en Colombia, Tercer Mundo Editores, Bogotá, I988; ZUBIRIA, S., "Comisión Histórica del Conflicto y sus Víctimas", Reporte: Contribuición AL entedimiento del conflicto armado en Colombia, Imprenta Nacional, Bogotá, 2015.

${ }^{16}$ FARJADO, D., "Comisión Histórica del Conflicto y sus Víctimas", Reporte: Contribución al entendimiento del conflicto armado en Colombia, Imprenta Nacional, Bogotá, 2015;

17 La Violencia generó múltiples escenarios de violencia, dejando un saldo de centenares de muertes y población desplazada. La Violencia acaba en 1958 con la instauración del Frente Nacional por el entonces general Gustavo Rojas Pinilla.Ver DUQUE, Karol Vanessa Ramirez, "Análise espacial...op. cit., p. 17

18 Ibídem.

19 ZUBIRIA, S., “Comisión Histórica del Conflicto...op. cit.
} 
En esta fase, el Gobierno colombiano implementó políticas neoliberales debilitando así el sector rura ${ }^{20}$, lo que favoreció un aumento gradual de las plantaciones ilegales y una intensificación del conflicto en forma de fortalecimiento de los grupos armados, paramilitares y asesinos a sueldo que se expandieron por las grandes ciudades ${ }^{21}$.

Freitas $^{22}$ identifica como las disputas más emblemáticas a la denominada Guerra de los Mil Días (1899-1902), la Violencia Famosa (1946-1958) y el reciente conflicto colombiano (I9602016). El autor destaca que la Guerra de los Mil Días acabó con la economía nacional y las fuerzas políticas; $y$ las víctimas ascendieron a más de 100.000 personas. Tras este periodo, gracias al aumento de las exportaciones de café y a la inversión de EEUU en los sectores del petróleo y la minería, Colombia protagonizó un crecimiento económico. Sin embargo, dicho crecimiento ocurre de forma desigual trayendo consigo el empobrecimiento de los sectores populares y medios; y provocando que esa parcela de población rompiese con los partidos tradicionales y con el apoyo histórico dado a las élites liberales. Es de resaltar que fueron estos sectores de población los que más tarde formarían los grupos armados de izquierda.

Frente a esta coyuntura y con el empeoramiento de las disputa entre el Partido Liberal y el ala de la izquierda protagonizadas en la elección presidencial de 1946, de acuerdo con Santos ${ }^{23}$, nuevas olas de violencia y asesinatos políticos se sucedieron en el país hasta el año 1958. En aquel periodo, tras diversas negociaciones entre el partido liberal y conservador, se estableció el Frente Nacional que determinaba la alternancia de ambos en el poder ejecutivo y en la división de los asientos en el legislativo.

Influidos por la alineación de la zona de influencia estadounidense y la consecuente persecución de la izquierda, estos partidos excluyeron otros sectores de la población - como los campesinos, los grupos de izquierda, los intelectuales, los sindicatos, los estudiantes y la nueva clase media urbana- de la vida político-institucional del estado ${ }^{24}$. En consecuencia, se inició otra ola de violencia. Es en este contexto cuando comenzaron a formarse los primeros movimientos de guerrilleros de izquierda del estado (1960), como las Fuerzas Armadas Revolucionarias de Colombia (FARC) y el Ejército de Liberación Nacional (ELN), que actúan como actores principales en el conflicto colombiano, dando el pistoletazo de salida al conflicto más reciente.

Freitas ${ }^{25}$ señala que más tarde, cuando la oligarquía colombiana no contaba con medios suficientes para derrotar a las guerrillas por la vía convencional - fuerzas policiales y militares regulares vinculadas al Gobierno-, buscó en la actividad ilícita del narcotráfico el camino para financiar la organización de tropas irregulares. Este hecho caracterizó la emergencia de los grupos paramilitares de derechas, conocidos por usar la violencia de forma indiscriminada. Esta cultura política de la violencia hunde sus raíces en la vida cotidiana de Colombia y, según argumenta

\footnotetext{
20 ESTRADA, A. J., "Orden neoliberal y reformas estructurales en la década del 90 . Un balance desde la experiencia colombiana” en Revista Ciencia política, UNAL, $\mathrm{n}^{\circ} \mathrm{I}, 2006$, pp. I4I-178.

21 GUTIÉRREZ, F.; PEÑARANDA, D., Mercados y armas: conflicto armado y paz en el periodo neoliberal: Latina America, una evolución, IEPRI, Revista La Carreta, Medellín, 2009.

${ }^{22}$ FREITAS, Pedro Jorge de, “América Latina em Guerra” en Revista Leituras da História, n 12, 2008.

23 SANTOS, Marcelo, “O conflito colombiano...op. cit.

${ }^{24}$ GUTIÉRREZ, F.; PEÑARANDA, D., Mercados y armas: conflicto armado...op. cit., p. 2 I

25 FREITAS, Pedro Jorge de, “América Latina em Guerra...op. cit.
} 
Kurtenbach, se fue instrumentalizando en diferentes sectores de la sociedad. Hecho que se ha registrado desde la independencia del país, des de que la oligarquía buscaba conseguir la integración clientelista de la población, hasta hoy en la forma en que los grupos armados hacen uso de la influencia para interceder en los procesos electorales y en la obtención de recursos económicos.

Es importante destacar que el conflicto en Colombia está así mismo relacionado con cuestiones territoriales, caracterizadas por un acceso desigual a la tierra y a otros recursos naturales ${ }^{26}$. Por un lado, el desplazamiento forzado era una estrategia de las partes en conflicto para que estas pudiesen ampliar su control sobre la tierra y los recursos. Por otro lado, la ausencia del estado, los derechos informales a la tierra y los altos niveles de pobreza y vulnerabilidad también fomentaron la desapropiación y el desplazamiento ${ }^{27}$.

Además, de acuerdo con los datos del IDMC se demuestra que el aumento del tráfico de drogas y la consecuente "guerra a la droga" entre el Gobierno, los cárteles y otros grupos armados, han sido los principales detonadores de la violencia y del desplazamiento desde el inicio de la década de los setenta. Así mismo, según el IDMC, las campañas de fumigación para acabar con las plantaciones de coca, junto con las operaciones de contra insurgencia y la incapacidad de evitar daños ambientales mayores o proporcionar alternativas económicas significativamente, en concreto a los agricultores pobres que cultivan las plantas de coca, exacerbaron aún más el conflicto.

En este contexto, la población fuer amenazada, desplazada y asesinada por grupos armados que asumieron el control de las minas, fuente importante de ingresos, especialmente para mitigar la inestabilidad de los precios de la cocaína. La minería de carbón del sector privado también desplazó a población en Colombia directamente a través de la adquisición de tierras e indirectamente por medio de la contaminación ambiental.

Por último, es necesario destacar que los desastres naturales también constituyen un importante factor para el desplazamiento en Colombia. El país cuenta con gran parte de su territorio cubierto por la cordillera de los Andes, así como con zonas de alto potencial sísmico y actividad volcánica.Algunas ciudades se ven expuestas a terremotos, inundaciones y deslizamientos de tierra; mientras que otras, como por ejemplo las ciudades pobres del litoral pacífico, sufren tsunamis. La rápida y no planeada urbanización, la alta densidad de asentamientos informales en áreas propensas al riesgo y una cantidad importante de construcciones edificadas violando las normas de seguridad provocaron que aumentara el riesgo de desastres en el país ${ }^{28}$.

\section{Principales actores del conflicto interno colombiano.}

${ }^{26}$ La economía colombiana está fundamentada principalmente en la agricultura y ganadería. Es el mayor productor mayor de esmeraldas y posee las mayores reservas de carbón mineral de América Latina. Entre los principales productos exportados por el estado están: petróleo, café, caña de azúcar, textiles y cuero.Ver KURTENBACH, Sabrine, Europe and the Colombian Conflict. Inter-American Dialogue, 2005. Disponible en http://archive.thedialogue.org/PublicationFiles/Europe\%20and\%20Colombia,\%20Kurtenbach\%20(June\%202005).pdf (consultado el I2 de diciembre de 2018), p. 16.

27 POSADA, Paola A., "Refugiados y desplazados forzados. Categorías de la migración forzada creadas como medidas de contención a las migraciones no deseadas” en Estudios Políticos, $n^{\circ} 35,2009$, pp. I3I-I 52.

${ }^{28}$ De acuerdo con el Internal Displacement Monitoring Centre-IDMC, estos desastres de inicio súbito fueron responsables por desplazar decenas de millares de personas todos los años entre 2008 y 2017 . El Centro revela que El Niño en 2010 llevó al desplazamiento de 3 millones de personas y niveles sin precedentes de inundaciones y deslizamientos de tierra en todo el país. 
Se muestra en el caso colombiano un vínculo directo entre la problemática nacional del desplazamiento y las dinámicas de los diversos actores del conflicto interno. La complejidad y la extensión en el tiempo del conflicto en Colombia dificultan la simplificación de los actores involucrados, especialmente debido a que se dio una diversificación de sus agentes a lo largo de su despliegue. En la lista de los grupos más activos en el conflicto y que ejercen mayor influencia para este fenómeno destacamos: entre las guerrillas, las Fuerzas Armadas Revolucionarias de Colombia (FARC) y el Ejército de Liberación Nacional (ELN); en lo que se refiere a los paramilitares, la Autodefensas Unidas de Colombia (AUC) y las Bandas Criminales (BACRIM), como consecuencia de la actuación en el territorio colombiano; además del propio estado, los narcotraficantes y EEUU.

\section{I. Las guerrillas en Colombia: FARC y ELN}

El surgimiento de las guerrillas en Colombia entre 1964 y 1965 fue consecuencia directa de una serie de acontecimientos, entre ellos: el agravamiento de la violencia, la exclusión política, la decadencia de los líderes políticos que apoyaban a la masa de la población, la economía fuertemente agraria y de latifundio, instituciones estatales debilitadas, la influencia ideológica desde el periodo de la Guerra Fría, especialmente por el alineamiento del estado con la política estadounidense, la concentración de la riqueza en las élites y los idearios del pensamiento comunista sobre algunos grupos sociales ${ }^{29}$. Las FARC y el ELN fueron los grupos que consiguieron actuar con mayor presencia en el escenario colombiano, especialmente dado el elevado contingente de combatientes. De acuerdo con Inácio ${ }^{30}$, fundadas a la luz de la tradición marxista-leninista, las FARC se autoproclamaron defensores de la población pobre rural frente a las élites.

Pécaut ${ }^{31}$ argumenta que no fue hasta principios de los años ochenta que las FARC salieron de su actitud más defensiva para adoptar una estrategia más militarizada y agresiva, con una perspectiva de toma de poder del estado. A lo largo de este periodo, el grupo expandió su zona de ocupación, especialmente como consecuencia del aumento de su participación en el tráfico de drogas, que a partir de ese momento pasó a controlar varias cadenas de producción, cobrando incluso impuestos a los plantadores de coca —el gramaje—32. Más allá del narcotráfico, los guerrilleros comenzaron a practicar con mayor intensidad la práctica de los secuestros, que en un inicio los usaban como forma para presionar al Gobierno, pero que más adelante se convirtieron en un medio de extorsión para recaudar fondos para la financiación del movimiento. Como principales impulsores para la adhesión al grupo, Felbab-Brown ${ }^{33}$, menciona que, a los factores previamente mencionados, se sumaban las debilidades institucionales del propio Estado colombiano y la extrema pobreza.

La expansión territorial de las FARC, según Santos ${ }^{34}$, vino acompañado de masacres,

\footnotetext{
29 SANTOS, Marcelo, “O conflito colombiano...op. cit., p. 22.

30 INÁCIO, César Dutra, “Conflito armado na Colômbia” en Revista Eletrônica Boletim do tempo, vol. 6, n 19,20I I. Disponible en http://tempo. tempopresente.org/index.php?option=com_content\&view=article\&id=2437:conflito-armado-na-colombia\&catid=207\&lang=es (consultado el 10 de Diciembre de 2018)

31 PÉCAUT, Daniel, As FARC: uma guerrilha sem fins?, Paz e Terra, San Paulo, 2010

32 Se resalta que, en los primeros años de su formación, las FARC eran contrarias a la producción y tráfico de cocaína.

33 FELBAB-BROWN,Vanda, "Shooting up: the impacto of illicit economies on military conflicto" en Massachusetts Institute of Technology, vol. 2, 2006. Disponible en http://hdl.handle.net/I72I.I/38600 (consultado el 21 de noviembre de 20I8), p. 640.

${ }^{34}$ SANTOS, Marcelo, “O conflito colombiano...op. cit.
} 
destrucción de pueblos, intimidaciones, reclutamiento de niños, provocando así un intenso desplazamiento forzado, especialmente en las poblaciones campesinas. Fue debido a este cuadro de violencia perpetrado por el grupo que, con la falta de interés en establecer un acuerdo de paz en las investiduras del Gobierno de Andrés Pastrana (1998-2002) y de Juan Manuel Santos (20I02018), se explica la pérdida de apoyo de las FARC por parte de la sociedad colombiana, que con el tiempo apoyaría al Gobierno ante la tentativa de marcar un camino para la paz en el país.

El Ejército de Liberación Nacional (ELN) surge en 1965 inspirado en la Revolución Cubana (1959) y es sensible al ideario de la Teología de la Liberación Cristiana, por tanto próximo a la Iglesia Católica y con un alineamiento con el pensamiento maoísta. En principio, el grupo adoptó un discurso semejante al de las FARC, contrario a la explotación económica colombiana, defendiendo la redistribución de la renta e instigando a la población a liderar una insurrección general contra el régimen. Sus principales miembros incluyen a la clase trabajadora urbana, así como a los sindicatos, campesinos, clase media, radicales católicos, intelectuales de izquierda y estudiantes ${ }^{35}$.

A diferencia de las FARC, que invirtieron en armas de guerra y en la formación de un ejército fuerte, el ELN siguió una línea más política caracterizada por un enfoque militar más simple, aunque también violenta, con un número de combatientes siempre inferior al de las FARC ${ }^{36}$. Esa capacidad militar reducida se dio tras una rápida expansión de los grupos paramilitares en bastiones tradicionales de guerrilla, estimulada tanto por la fuerte política de seguridad adoptada durante el Gobierno de Uribe (2002-2009), como por la competición con las FARC en la búsqueda de zonas de influencia.

El apoyo económico del grupo a lo largo de la década de los ochenta se basó en la obtención de recursos naturales y en la práctica de extorsión y secuestro. No obstante en los años noventa, la implicación con el tráfico de drogas se volvió evidente y con ello pasó a ser una de las principales fuentes de ingreso del $E L N^{37}$. Más tarde, Santos ${ }^{38}$ afirma que reconociendo la capacidad militar del grupo, la administración de Uribe trató de establecer un diálogo de paz con el ELN - iniciadas formalmente en Cuba en 2005-, pero que no llegaron a buen puerto y cesaron en 2007. En esta perspectiva, a pesar de todos los contratiempos militares y con pocos recursos económicos, la guerrilla permanece organizada en el territorio colombiano.

\subsection{Los paramilitares: AUC y BACRIM}

Según Rivera ${ }^{39}$, el paramilitarismo en Colombia surge en parte por la deficiencia estatal para mantener el orden y la estabilidad interna. En el periodo anterior al de "la Violencia", el estado ya daba señales de debilidad institucional y de declive en la protección de la población, presentando dificultades para mantener el monopolio de la fuerza en el territorio. Fue en este contexto cuando comenzaron a surgir ejércitos privados, aunque informalmente, sin que hubiese grandes restricciones por parte del gobierno que años más tarde daría legitimidad a la existencia de estos

\footnotetext{
35 PÉCAUT, Daniel, As FARC: uma guerrilha sem fins...op. cit., p. 29.

36 INTERNATIONAL CRISIS GROUP, Colombia's FARC Conflict. Internactive Presentations, 2009. Disponible en https://www.crisisgroup.org/latinamerica-caribbean/andes/colombia/interactive-colombias-farc-conflict (consultado el 10 de diciembre de 20I8)

37 FELBAB-BROWN,Vanda, “Shooting up: the impact of...op. cit., p. 327.

38 SANTOS, Marcelo, “O conflito colombiano...op. cit.

39 RIVERA, “Edgar de Jesús Velásquez. Historia del paramilitarismo en Colombia” en História, vol. 26, n I, 2007, pp. I34-I53.
} 
grupos de autodefensa ${ }^{40}$.

De hecho, se puede argumentar que las fuerzas paramilitares en Colombia ganaron legitimidad gracias a la conjugación de factores domésticos e internacionales, como: la lógica bipolar de la Guerra Fría y el aumento de los conflictos sociales, especialmente tras la creación de las FARC y del ELN. Rivas Nieto y García (2008) afirmaron que el Decreto $n^{\circ} .3398$ (1965) y la Ley $n^{\circ} .45$ (1968) concretaron la formalización de estas fuerzas, ya que fueron las pioneras en establecer las bases legales para la creación de las organizaciones de defensa civil.

Dotados de una ideología conservadora y anticomunista, los grupos de autodefensa iniciaron su actuación como una estrategia defensiva, limitada no solo a incluir los movimientos guerrilleros, sino también pasaron a actuar a favor de los terratenientes $y$, más tarde, de los narcotraficantes, con el fin de garantizar la manutención y la explotación de la tierra ${ }^{41}$. Bagley $y^{42}$ argumenta que el fortalecimiento del narcotráfico potenció el conflicto interno en sus diferentes frentes, ya que fue así como se produjo en las guerrillas; la industria de la droga pasó a financiar el paramilitarismo que comenzó a asumir prácticas cada vez más violentas contra la población civil y los grupos rebeldes, con vistas a atender a los intereses de los narcotraficantes.

En aquella coyuntura, surgieron innumerables frentes de paramilitares actuando de forma descentralizada. No fue hasta la década de los noventa que tuvieron lugar los primeros movimientos para unificar estos grupos, lo cual dio lugar a la creación de las Autodefensas Campesinas de Córdoba y Urabá (ACCU), que más tarde contribuyeron a construir una coordinación nacional llamada Autodefensas Armadas de Colombia (AUC). De acuerdo con Rico ${ }^{43}$, las AUC controlaban 7II municipios colombianos, con su financiación en un $70 \%$ dedicado al mercado de la droga. Las AUC actuaron en el territorio colombiano durante cerca de 10 años, siendo disuelta entre 2003 y 2006 tras un acuerdo de paz con el Gobierno Uribe.

Santos $^{44}$ destaca que las AUC dejaron un legado sangriento repleto de masacres, intimidaciones, corrupción estatal, asesinatos colectivos, desapariciones, control social y políticos de diversas localidades, además de que provocasen el desplazamiento de millones de personas. De este modo, lo que al principio tenía que ser solo un combate entre guerrillas, se convirtió gradualmente en una serie de actividades ilícitas, como el desvío de dinero público, la venta ilegal de gasolina, el robo de tierras y el control de los negocios de la droga ${ }^{45}$.

Esta política de apoyo del gobierno a la formación paramilitar tuvo como resultado la persistencia de este fenómeno en el territorio, dado que el proceso de desestructuración parcial

\footnotetext{
40 RIVAS NIETO, Pedro; GARCÍA, Pablo Rey, Las autodefensas y el paramilitarismo en Colombia ( $1964-2006)$, Confines de Relaciones Internacionales y Ciencia Política, Monterrey, 2008, p. 43.

4 INTERNATIONAL CRISIS GROUP, Colombia's FARC Conflict...op. cit.

42 BAGLEY, Bruce Michael, “Narcotráfico, violencia política y política exterior de Estados Unidos hacia Colombia en los noventa” en Revista Colombia Internacional, $\mathrm{n}^{\circ}$ 49-50, 2000, pp. 05-38.

${ }^{43}$ RICO, Daniel M., “Las Dimensiones Internacionales del Crimen Organizado en Colombia: Las Bacrim, sus Rutas y Refugios” en GARZÓN, Juan Carlos; OLSON, Eric L. (orgs.), La diáspora criminal: la difusión transnacional del crimen organizado y cómo contener su expansión, Woodrow Wilson International Center for Scholars, Pennsylvania, 2013

${ }^{44}$ SANTOS, Marcelo, “O conflito colombiano...op. cit.

45 Ibídem, pp. 35-36.
} 
no incluyó acuerdos sobre el tráfico de drogas, principal vínculo establecido por los paramilitares. Así, desde entonces, nuevas estructuras de grupos criminales comenzaron a surgir, como fue el caso de los Bandas Criminales (BACRIM). Estos grupos se componen en su mayoría por comandantes paramilitares de rango medio que continuaron operando en diferentes organizaciones para llenar el vacío que dejaron las AUC.

Existen innumerables debates políticos, legales y académicos sobre las BACRIM, que presentan las semejanzas y diferencias frente al paramilitarismo ${ }^{46}$. Las investigaciones que se plantean giran en torno a si esos grupos podrían ser considerados como la próxima generación de paramilitares o si son simplemente pandillas criminales. Aunque no exista consenso sobre su denominación, es indiscutible la correlación entre estas bandas criminales y el paramilitarismo colombiano. De hecho, las BACRIM se constituyeron como organizaciones híbridas, combinando rasgos del paramilitarismo con estructuras propias de la mafia y operaciones criminales, al ejercer además el tráfico de drogas y de otras actividades criminales, como la extorsión y la minería ilegal, así como una serie de abusos generalizados contra la población civil, tales como masacres, asesinatos; cuestiones que estimularon el desplazamiento forzados a gran escala ${ }^{47}$.

\subsection{El estado colombiano y Estados Unidos}

Los casi 60 años de conflicto han vivido momentos diversos, como resultado de la coyuntura con causas y actores variados. Aunque el Estado colombiano haya asumido, en buena parte por sus gobiernos, una política de combate ante el conflicto armado, sus posiciones han sido heterogéneas y provocativas ${ }^{48}$. Más allá de la incapacidad de enfrentarse militarmente a los grupos ilegales, el estado ha adoptado políticas que han favorecido las élites y han debilitado su relación con los sectores más pobres de la población -incrementadas por las deficiencias en relación a la cuestión agraria - además de su posición ideológica favorables a los intereses estadounidenses.

En las décadas iniciales del conflicto —entre 1960 y 1970—, las principales actividades de las guerrillas se concentraban en las áreas de ausencia estatal, por lo que los combates ocurrían en las zonas rurales y de la periferia. En esta fase de disputas internas, la mayor parte de los gobiernos puso en marcha una dura política de represión influida por la lógica de seguridad de Estados Unidos ${ }^{49}$.

Los primeros intentos de resolución del conflicto no se iniciaron hasta mediados de los años ochenta, aunque la mitigación de las disputas por medio de las negociaciones fueron precipitadas y acabaron fracasando, abriendo así un espacio para el recrudecimiento de la violencia, al tiempo que se observó un aumento en el número de actores armados y una expansión en el territorio. Kurtenbach ${ }^{50}$ señala que en este periodo, los grupos criminales se instalaron en el estado y pasaron a tener influencia directa en el fenómeno paramilitar y en las guerrillas, desestabilizando el sistema político.

46 RICO, Daniel M.,“'Las Dimensiones Internacionales del...op. cit., p. 4.

47 HUMAN RIGHTS WATCH, The risk of returning home: violence and threats against displaced people reclaiming land in Colombia, Human Rights Watch, USA, 20I3. Disponible en https://www.hrw.org/report/2013/09/I7/risk-returning-home/violence-and-threats-against-displacedpeople-reclaiming-land (consultado el 10 de diciembre de 2018), p. 16.

48 SANTOS, Marcelo, “O conflito colombiano...op. cit., p. 38.

49 Ibídem

50 KURTENBACH, Sabrine, Europe and the Colombian Conflict...op. cit. 
A mediados de los años noventa, Santos ${ }^{51}$ afirma que la crisis política impregnó la economía del estado y que aunque se llevaron a cabos reformas democráticas iniciadas por la Constitución de 1991, esfuerzos de pacificación por parte del Gobierno -especialmente por el presidente Andrés Pastrana, 1998-2002 - toda iniciativa volvió a fracasar. Con esta perspectiva de profunda crisis política, económica y social, el Estado colombiano terminó por perder su estatus en el panorama internacional, contribuyendo a que actores externos interfiriesen en sus asuntos internos, como fue el caso de EEUU, con el objetivo de encontrar nuevas formas de plantar cara al narcotráfico y a grupos ilegales.

En este escenario, la entrada estadounidense respondía a la suma tanto de factores internos en Colombia, como a una estrategia deliberada de EEUU de aumentar la presencia militar en la región andino-amazónica ${ }^{52}$ y con la intención de controlar las protestas sociales y permitir la aplicación de políticas neoliberales.

Así mismo, la actuación de EEUU corresponde con un cambio de la percepción de la política estadounidense frente a Colombia con una convergencia de los siguientes factores: en primer lugar, el fenómeno del narcotráfico adquirió un lugar predominante en la agenda de seguridad de EEUU y en ese proceso Colombia se había convertido en el epicentro del tráfico de drogas; en segundo lugar, tuvo lugar una intensificación de la participación de los grupos armados ilegales en la cadena de producción de la droga;y por último, la presión de los países vecinos ante el empeoramiento del impacto del conflicto para la región ${ }^{53}$.

De hecho, la evolución del conflicto colombiano es resultado de la propia complejidad de los fenómenos existentes tanto dentro como fuera de sus fronteras, como ejemplo es el crimen organizado, el tráfico de drogas y contrabando de armas, el lavado de dinero y dos uniones de esos sistemas con asociaciones políticas ilegales y con grupos de guerrillas considerados como uno de los mayores desafíos en el área de seguridad internacional.

En diciembre de 2016, el Gobierno colombiano —en la presidencia de Juan Manuel Santos- y los miembros de las FARC firmaron un acuerdo de paz con vistas a poner fin al conflicto armado. Además del desarme de las FARC, el acuerdo preveía la eliminación del cultivo de drogas ilícitas y la creación de programas sociales para insertar a más de 6.000 rebeldes en la sociedad civil. Jerônimo Rios ${ }^{54}$ argumenta que, por un lado, este acuerdo encerraba el último reducto de la Guerra Fría en América Latina. Por otro, el autor afirma que, aunque imperfecto, puede ser considerado el mejor acuerdo firmado desde 1989, puesto que involucró elementos importantes como la descentralización, la participación ciudadana, la democracia local, el pluralismo político y particularmente el desarme y la justicia transicional que ofrecería una gran oportunidad para que Colombia tomase como éxito el proceso de normalización política y económica y la recomposición del tejido social.

\footnotetext{
5I SANTOS, Marcelo, "O conflito colombiano...op. cit.

52 PENNAFORTE, Charles, "Colômbia e as Bases Militares dos Estados Unidos" en Revista Geografia, 20II. Disponible en http:/l conhecimentopratico.uol.com.br/geografia/fenomenosterrestres/soluções/busca.asp? $\mathrm{t}=$ Charles\%20Pennaforte (consultado el 10 de enero de 2014)

53 ROJAS, Diana Marcela, “Estados Unidos e la Guerra en Colombia” en GUTIÉRREZ, Francisco; WILLIS, María Emma; GÓMEZ, Gonzalo, Sánchez (orgs.), Nuestra guerra sin nombre: transformaciones del conflicto en Colombia, Grupo Editorial Norma, Bogotá, 2005, pp. 43-45.

${ }^{54}$ RÍOS, Sierra, Jerónimo, Breve historia del conflicto armado en Colombia, Los Libros de la Catarata, Madrid, 20 I 7, pp. I I0-I I 2.
} 
Un año después de la firma del acuerdo, grupos guerrilleros siguieron luchando durante meses para asumir los territorios que estaban bajo el control de las FARC antes de su disolución tras el acuerdo de paz. Varias noticias apuntan a una mayor movilización, por ejemplo, de las BACRIM en el sentido de aumentar su área de actuación, lo cual viene ocurriendo desde la desmovilización de las FARC. El Gobierno colombiano ha intentado ratificar partes importantes del tratado $y$, al mismo tiempo, ha luchado por asumir el control de las áreas anteriormente controladas por las FARC. La disputa por los territorios también implica cuestiones relacionadas con las rutas del narcotráfico, las redes de extorsión, entre otras cuestiones inherentes a la compleja configuración del conflicto que asoló Colombia durante tantas décadas y que ahora da señales de retorno.

El hecho es que informes recientes de agencias internacionales y en Colombia, tal y como se ha citado anteriormente, señalan un aumento vertiginoso de la violencia y, por extensión, un crecimiento de los desplazados internos que sitúan a Colombia como el país con el mayor número de desplazados internos del mundo.

\section{La comunidad internacional ante el problema del desplazamiento interno}

Las migraciones han sido parte de la historia de la humanidad desde el origen y sus flujos de población acabaron afectando la política doméstica, la seguridad nacional, las relaciones bilaterales, multilaterales y regionales de los estados alrededor del mundo. Por diferentes motivos, el movimiento de personas se intensificó creando cambios en el escenario mundial. Durante el siglo XX, el crecimiento de la desigualdad entre países, las guerras, la xenofobia, el estancamiento económico, la urgencia de políticas migratorias restrictivas, así como la violación sistemática de los derechos humanos agravaron el fenómeno del desplazamiento forzado. De forma paralela, el cierre de las fronteras y la existencia de nuevos actores en el contexto del conflicto armado contribuyeron decisivamente para la repercusión del problema a gran escala ${ }^{55}$.

El término "desplazados internos" aparece recientemente y deriva de un acuerdo del acuerdo de paz firmado para el cese del conflicto en Sudán en los años setenta ${ }^{56}$. En él se hacía referencia al grupo de población desplazada dentro del contexto particular de una actuación de emergencia que promoviese el reasentamiento y rehabilitación de estas personas y, por eso, no tenía una connotación que proporcionase un precedente para la reivindicación de garantías normativa ${ }^{57}$.

De hecho, las primeras iniciativas multilaterales para esta temática surgen, únicamente a finales de los años ochenta, a partir de dos conferencias: la Conferencia Internacional sobre el problema de los refugiados, repatriados y personas desplazadas en el sur de África (1988) y la Conferencia Internacional sobre Refugiados centroamericanos (CIREFCA-1989) ${ }^{58}$. Realizadas bajo el amparo de las Naciones Unidas, estos dos paneles de discusión dieron difusión a la problemática

\footnotetext{
55 CASTLES, Stephen, “The International Politics of Forced Migration” en Development, vol. 46, $n^{\circ}$ 3, 2003, pp. I I-20. Disponible en http:// econpapers.repec.org/article/paldevelp/ v_3a46_3ay_3a2003_3ai_3a3_3ap_3al I-20.htm (consultado el 25 de Mayo de 20I3), p. I I.

56 El Acuerdo Addis Abeba, que fue celebrado en 1972 no ámbito de la ONU, hace referencia a las personas desplazadas en sus artículos $9^{\circ}$ y $10^{\circ}$.

57 PHUONG, Catherine, The international protection of internally displaced persons, Cambridge University Press, Cambridge, 2005, p. I4.

58 OLIVEIRA, Eduardo Cançado. “A proteção jurídica internacional dos deslocados internos” en Revista do Instituto Brasileiro de Direitos Humanos, vol. $5, n^{\circ} 5,2004$, p. 76.
} 
de las PDI como un fenómeno generalizado, aunque no implicaron grandes avances, ya que el principal asunto debatido en esta época aún se centraba en la temática de los refugiados.

La comunidad internacional, que tardó en ofrecer respuestas para esta temática, estaba preocupada por encontrar soluciones para la ya compleja cuestión de los refugiados. Por tanto, el periodo posterior a 1945 fue testigo de la construcción de mecanismos jurídico-institucionales creados para la protección de estas personas. Como resultado, la ONU aprobó en 195I, en Ginebra, la Convención Relativa al Estatuto de los Refugiados y la creación del Alto Comisionado de las Naciones Unidas para los Refugiados ${ }^{59}$.

En este contexto, el fenómeno del desplazamiento interno permanecía sin respuesta y carente de soluciones debido a la analogía que se hacía en relación con los refugiados. Las semejanzas y diferencias con esta categoría migratoria, así como los factores que interviene durante el proceso de desplazamiento, dificultaron la separación de estos campos, ocasionando hasta una confusión conceptual entre los dos términos.

La confusión más común entre los dos términos es, la mayoría de las veces, por las mismas razones que justifican tanto el desplazamiento interno como el refugio, excepto el hecho de no haber una normativa internacional específica dirigida a la protección de los PDI, que acaban utilizando el aparato del derecho internacional de los derechos humanos y humanitario para conseguir algún tipo de amparo.

De acuerdo con $A C N U R^{60}$, los desplazados internos representan "grupos numerosos de personas que han sido forzadas, de forma súbita o inesperada, a abandonar sus hogares y a establecerse en lugares diferentes de su país, debido a conflictos armados, luchas internas, violaciones sistemáticas de derechos humanos o desastres causados por el hombre", de forma análoga, refugiado es "alguien que al temer ser perseguido por motivos de etnia, religión, nacionalidad, grupo social u opiniones políticas, se encuentra fuera de su país y que no puede o, como consecuencia de ese miedo infundado, no quiere acogerse a la protección de su país"6!.

Es importante destacar que el abordaje en torno a la conceptualización del término “desplazamiento interno" o "Personas Desplazadas Internamente"62 sigue un patrón descriptivo y no jurídico, simplemente porque,

"[...]describe la situación de hecho de una persona desarraigada en su propio país de residencia. No confiere un estatuto jurídico ni derechos específicos como sí ocurre en el caso de los refugiados. En el caso de los desplazados internos esto no es necesario porque, a diferencia de los refugiados, que requieren un estatuto jurídico especial por el hecho de encontrarse fuera de su país de origen

\footnotetext{
59 CUNHA, Guilherme da, "Migrantes e refugiados: marco jurídico e estratégia no limiar do século XXl” en PINHEIRO, Paulo Sérgio; GUIMARÃES, Samuel Pinheiro (orgs), Direitos humanos no século XXI, IPRI/ FUNAG, Brasilia, 2002, p. 503.

60 ORGANIZACIÓN DE NACIONES UNIDAS, Alto Comissariado das Nações Unidas para Refugiados - ACNUR, Who we help: internally displaced people: On the run in their own land, 20I3. Disponible en http://www.unhcr.org/pages/49c3646cl 46.html (consultado el 22 de mayo de 2013)

61 ORGANIZACIÓN DE NACIONES UNIDAS, Assembleia Geral das Nações Unidas - AGNU: Convenção relativa ao estatuto dos refugiados (Resolução A/RES/429(V), aprovada em 28 de julho de 195I). 195I. Disponible en http://www.acnur.org/t3/fileadmin/scripts/doc.php?file=t3/ fileadmin/Documentos/portugues/BDL/Convencao_relativa_ao_Estatuto_dos_Refugiados (consultado el I3 de noviembre de 20I3), art. I ${ }^{\circ}$, c.

62 Por ser los términos similares, se usarán indistintamente a lo largo del trabajo.
} 
y carecer de la protección del mismo, los desplazados internos mantienen todos sus derechos y garantías como cualquier otro ciudadano o residente habitual en su país"

Al contrario de los refugiados, el desplazamiento interno tiende a ser menos visible y, por consiguiente, la concienciación y solidaridad internacional aparecen en menor grado, lo cual significa que sus víctimas dependen en casi su totalidad de la capacidad de respuesta del estado. Sin embargo, lejos de ser un problema temporal y de consecuencias limitadas, el desplazamiento interno tiene impacto de larga duración para las regiones en las que ese fenómeno sucede. Se trata de un fenómeno nefasto que crea un desequilibrio social, económico $y$, a menudo, político y afecta no solo a las personas obligadas a huir, sino también a las que permanecen en comunidades abandonadas o que viven en regiones para las que los desplazados se dirigen. Sus efectos son devastadores para familias, culturas, países y hasta regiones enteras. Las consecuencias externas, aunque menos evidentes que las causadas por el flujo de refugiados, son igualmente nefastas para la estabilidad y para el desarrollo ${ }^{64}$.

Teniendo en cuenta este hecho, la sociedad de estados, a mediados de la década de los noventa, pasó a discutir con preocupación el tema, ya que lo referido no podría continuar al margen de las discusiones internacionales debido a las posibles amenazas que su extensión podría provocar para el mantenimiento del orden y la paz mundial.

En este contexto, la Comisión de Derechos Humanos de la ONU —motivada por el primer informe de análisis sobre los desplazados internos, presentado por el entonces secretario general Boutros Boutros-Ghali (1992-1996) - abrió camino para un examen específico sobre el desplazamiento interno al aprobar la resolución 1992/73, como intento de establecer un representante especial que se dedicase al estudio del tema y que pudiese obtener información de todos los gobiernos con relación a los desplazados internos, incluyendo la investigación de la norma - derecho humanitario, derecho internacional de los derechos humanos y derecho internacional de los refugiados - que podría ser aplicada en la asistencia de las PDI. Con este objetivo, el diplomático sudanés Dr. Francis Deng fue nombrado Representante Especial del secretario general para Desplazados Internos y asumió la responsabilidad de emitir nuevos informes ${ }^{65}$.

En este mismo periodo, laAsamblea General determinó la creación del puesto de Emergency Relief Coordinator (ERC), que coordinaría las actividades de la también recién constituida InterAgency Standing Comitee (IASC), con el fin de garantizar la atención en emergencias de los casos de desplazamiento forzado. Esta agencia, bajo la orientación del ERC, creó un grupo de trabajo para las PDI que operó durante cinco años, a través de la actuación conjunta de diversos órganos especializados integrados en la estructura de la ONU, como ACNUR, el Programa de Naciones Unidas para el Desarrollo (PNUD), el Programa Mundial de Alimentos (PMA), el Fondo

63 ORGANIZACIÓN DE NACIONES UNIDAS, "Alto Comissariado das Nações Unidas para Refugiados - ACNUR: Grupo de trabalho do Grupo Setorial Global de Proteção”, Manual para la protección de los desplazados internos, 20 I0. Disponible en http://www.refworld.org/cgi-bin/ texis/vtx/rwmain/opendocpdf.pdf?reldoc=y\&docid=5I54I9462 (consultado el 2 de mayo de 20I3), pp. 08-09.

64 OLIVEIRA, Eduardo Cançado. “A proteção jurídica internacional...op. cit., p. 75.

65 WEISS, Thomas; KORN, David, Internal displacement: conceptualisations and its consequences, Routlege, Londres, 2006, p. 02. 
de Naciones Unidas para la Infancia (UNICEF), la Organización Mundial de la Salud (OMS) y la Organización Internacional de Migraciones (OIM), conjuntamente con el Comité Internacional de la Cruz Roja (CICR), con el objetivo de identificar las principales dificultades a las que se enfrentan las poblaciones desplazadas y así poder movilizar esfuerzos y dar respuesta a las situaciones de emergencia en operaciones en terreno ${ }^{66}$.

Tras sucesivas consultas, Francis Deng presentó un informe ${ }^{67}$, alertando de la incapacidad de los desplazados internos a la hora de encontrar lugares seguros, de que a menudo se encuentran en situaciones de vulnerabilidad ante violaciones de derechos humanos, que se les está privando de sus necesidades básicas como la vivienda, la educación, la salud y los alimentos. Dicho informe también apuntaba que la respuesta de la comunidad internacional frente al fenómeno del desplazamiento debería surgir del esfuerzo por recopilar reglas y normas existentes para así formular principios generales que pudiesen liderar el trato de esta parte de la población.

Al mismo tiempo, señaló que la ausencia de mandatos claros y la respuesta internacional por medio de arreglos ad hoc y de la acción subsidiaria de algunas agencias especializadas ha sido limitada e insatisfactoria, lo cual exigiría la creación de un grupo de trabajo específico y la existencia de un Relator Especial para analizar la situación. A partir de eso, propuso, como solución al problema de la responsabilidad institucional, en relación a los desplazados, tres probables caminos: la atribución de la responsabilidad de protección a una agencia especializada ya existente; la creación de una nueva agencia, de forma similar al ACNUR; o el establecimiento de un mecanismo de movilización de las actividades entre las diversas agencias, órganos y organizaciones existentes ${ }^{68}$.

Como consecuencia de dicho informe, la respuesta internacional al problema del desplazamiento se reestructuró según el enfoque colaborativo, es decir, las agencias especializadas de la ONU y otras instituciones internacionales asumirían la responsabilidad conjunta de proporcionar asistencia a los desplazados. El secretario general, sospesando argumentos de viabilidad política, apoyó ese planteamiento y reafirmó la responsabilidad del ERC en garantizar protección y asistencia a las PDI, ya que no existía ni voluntad política, ni recursos financieros para crear una nueva agencia. La posibilidad de extensión del mandato del ACNUR, para asumir plena responsabilidad sobre las PDI, también fue rechazada con el argumento de que sobrecargaría a la agencia, puesto que el problema presenta una extrema gravedad y una proporción enorme para que sea atendido por una única agencia ${ }^{69}$.

66 PHUONG, Catherine, The international protection of internally...op. cit., Pp. 103-104.

${ }^{67}$ ORGANIZACIÓN DE NACIONES UNIDAS, Conselho Econômico e Social das Nações Unidas - ECOSOC, Commission on Human Rights, "Comprehensive study prepared by Mr. Francis M. Deng, Representative of the Secretary-General on the human rights issues related to internally displaced persons, pursuant to Commission on Human Rights resolution 1992/73" en Further promotion and encouragement of human rights and fundamental freedoms, including the question of the programme and methods of work of the commission, Documento E/CN.4/I993/35, 2I de enero de 1993. Disponible en http://www.unhchr.ch/Huridocda/Huridoca.nsf/TestFrame/fb36ada4f4e26ce68025672f003ef984 (consultado el 13 de noviembre de 2013). En este estudio fueron identificadas 17 áreas que requerían protección para los desplazados internos, además de ocho lagunas claras en la legislación internacional. No había, por ejemplo, una norma que garantizara explícitamente la prohibición del regreso forzado de personas internamente desplazadas a los locales de peligro, del mismo modo que no existía un derecho de restitución de los bienes perdidos como consecuencia del desplazamiento durante el conflicto armado. Además, eran necesarias garantías especiales para mujeres y niños, y leyes que regulasen las condiciones de los asentamientos para los desplazados. Ver COHEN, Roberta, "The Guiding Principles on Internal Displacement:...op. cit., p. 31

${ }^{68}$ ORGANIZACIÓN DE NACIONES UNIDAS, Conselho Econômico e Social das Nações Unidas - ECOSOC, Commission on Human Rights, "Comprehensive study...op. cit., pp. 277-292.

69 OLIVEIRA, Eduardo Cançado. “A proteção jurídica internacional...op. cit., p. 77. 
En este espacio, un grupo de expertos, vinculados a los organismos de la ONU y con las ideas del informe presentado por Deng muy presentes, iniciaron un proceso de investigación, que reconocería, a partir de los instrumentos normativos ya existentes -Derecho Internacional Humanitario (DIH), Derecho Internacional de los Derechos Humanos (DIDH) y el Derecho Internacional de los Refugiados-, los que podrían aplicarse para la atención y protección de las $\mathrm{PDI}^{70}$.

Dicha investigación tuvo como resultado la redacción de los llamados Principios-Guía sobre el Desplazamiento Interno ${ }^{71}$ documento en el cual convergían los tres ámbitos del derecho internacional citados previamente ${ }^{72}$. Los Principios Rectores relativos al desplazamiento interno se sometieron a la aprobación de la Comisión de Derechos Humanos en 1998 por el entonces secretario general de la ONU sobre la cuestión de los desplazados internos, Francis Deng.

Desde entonces, los Principios Rectores han servido como "normal internacional para orientar a los gobiernos, las organizaciones internacionales/regionales y todos los actores pertinentes en la provisión de asistencia y protección a los desplazados internos”, y, aunque no tiene un carácter normativo vinculante, los principios reflejan y son consecuentes con el Derecho Internacional, puesto que identifican los derechos y garantías relacionadas con la protección de las PDI, teniendo en cuenta las vulnerabilidad específicas a las que se enfrentan ${ }^{73}$.

\section{Mecanismos cooperativos para la solución de problemas comunes}

Antes de investigar la actuación de las instituciones internacionales en el caso colombiano, se hace necesario examinar el contexto en el cual se originó la necesidad de establecer mecanismos cooperativos para la solución de problemas comunes y de grande complejidad entre los estados.

Es importante tomar nota que, en el campo de estudio de las relaciones internacionales, han predominado análisis que apuntan para la estructura anárquica del sistema internacional, caracterizada por la "ausencia de una autoridad suprema, legítima e indiscutible que pueda dictar las reglas, interpretarlas, implementarlas y castigar a quien no las obedece"74, cuya condición contribuye para formar un escenario de indeterminaciones y constantes cambios.

Así, para algunas corrientes teóricas, esa condición de aparente desorden puede ser suprimida en la medida que haya una posibilidad de transformar las relaciones interestatales

70 DARIO, Diogo Monteiro, “As Populações Internamente Deslocadas pelo conflito colombiano durante o governo Uribe: uma reflexão sobre os usos da segurança humana na era da Guerra contra o Terror”, Dissertação (Mestrado em Relações Internacionais) - Pontifícia Universidade Católica do Rio de Janeiro, Rio de Janeiro, 2009. Disponible en http://www.maxwell.lambda.ele.puc-rio.br/I4094//4094_I.PDF (consultado el 23 de junio de 2013), p. III.

71 ORGANIZACIÓN DE NACIONES UNIDAS, Alto Comissariado das Nações Unidas para Refugiados - ACNUR. Princípios Orientadores Relativos aos Deslocados Internos - PORDI. 1998. Disponible en http://www.ohchr.org/Documents/lssues/IDPersons/GPPortuguese.pdf (consultado el 13 de Noviembre de 2013)

72 De acuerdo con Cohen y Deng, la decisión de la formulación de un conjunto de principios, en vez de elaboración de otro instrumento normativo vinculante como una convención, ocurrió por tres razones: primero porque existía el recelo de que un tratado pudiese afectar a la soberanía nacional, segundo porque la elaboración de una convención demandaría mucho tiempo y la temática requería urgencia y, por último, creían que el cuerpo normativo existente era suficiente y, por tanto, era necesaria únicamente una reformulación de las reglas existentes para producir mejores respuestas a los problemas de las PDI.Ver COHEN, Roberta; DENG, Francis Manding, "Orígenes y desafíos" en Revista Migraciones Forzadas:Alicante, Diez años de los principios rectores del desplazamiento interno, 2008, p. 4.

73 GLOBAL DATABASE, Guiding Principles on Internal Displacement:The guiding principles: Introduction to the guiding principles”, 20I3. Disponible en http://www.idpguidingprinciples.org/ (consultado el 24 de Mayo de 20I3)

${ }^{74}$ NOGUEIRA, João Pontes; MESSARI, Nizar, Teoria das Relações Internacionais: correntes e debates, Campus - Elsevier, Rio de Janeiro, 2005 , p. 26 
en un ambiente más cooperativo y diplomático. Hecho que, en cierta medida, ocurrió debido al surgimiento de nuevos e importantes actores en la arena política internacional.

De forma general, ese cuadro de interdependencia derivó de dos macroprocesos articulados que promovieron una reconfiguración del sistema político internacional: el primero con respecto a la intensificación del proceso de globalización; y el segundo, la disolución del bloque socialista y el fin de la lógica dictada por la bipolaridad.

En consecuencia, la visión realista ${ }^{75}$ del estado-nación como único actor influyente en el sistema internacional, comenzó a ser cuestionado y, con eso, actores no estatales - como las instituciones internacionales, regímenes, organizaciones globales y regionales, las comunidades epistémicas ${ }^{76}$, organizaciones no gubernamentales, grupos insurgentes y terroristas, individuos, empresas multinacionales y medios - se mostraron como agentes potencialmente capaces de ejercer influencia en el comportamiento de los estados $y$, consecuentemente, en el contexto externo.

En la estela de este proceso, el pensamiento liberal de las relaciones internacionales ${ }^{77}$, pasó a entender el estado tanto como un mal necesario como una posible amenaza, teniendo en cuenta que, así como él era indispensable para proteger los individuos contra los peligros externos y contra grupos o personas que, internamente, no respetan el dominio de la ley, es también, aún en el ámbito interno, considerado un riesgo para el ejercicio del poder y una amenaza a las libertades individuales de los ciudadanos ${ }^{78}$.

Así, la imagen de la sociedad internacional fue, poco a poco, transitando entre el modelo de una "comunidad de estados civilizados", motivada por los intereses de poder y formada por la competición, para el de una "sociedad civil mundial" en busca de una regulación entre las diferentes naciones y fundamentada en la cooperación. Ese paso, en las palabras de Smouts ${ }^{79}$, condujo a la revisión gradual del concepto de cooperación internacional que había sido, inicialmente, pensado en términos de poder y derecho.

Eso porque, hasta la Primera Guerra Mundial, las relaciones interestatales fueron esencialmente pautadas en el derecho de coexistencia, destinado a imponer obligaciones a los estados, con la intención de promover los principios de soberanía e igualdad, de forma que se

\footnotetext{
75 El abordaje realista de las relaciones internacionales surgió en el periodo entreguerras (1919-1939) inspirado en los escritos clásicos de Tucídides, Maquiavelo, Hobbes, Hegel yWeber. Elementos centrales en la visión realista: estatocentrismo, poder, anarquía, estado de naturaleza de guerra de todos contra todos. Ibídem, pp. 20-24)

76 De acuerdo con Haas, comunidad epistémica es una red de profesionales con reconocida experiencia y competencia en un dominio específico del conocimiento, que se articulan a los estados ayudándolos a identificar sus intereses dentro de esta área de dominio, proponiendo políticas específicas e identificando puntos importantes para la negociación. Para este autor, el control sobre el conocimiento y la información es una dimensión importante de poder, pues la difusión de nuevas ideas e informaciones puede llevar a nuevos padrones de comportamiento o incluso volverse un importante determinante en la coordinación de la política internacional.Ver HAAS, Peter M., “Introduction: Epistemic communities and international policy coordination” en International Organization, Cambridge, vol. 46, $\mathrm{n}^{\circ}$ I, I992, p. 3.

77 La perspectiva liberal de las relaciones internacionales también surgió en el periodo entreguerras (1919-1939) inspirada en los escritos clásicos de Aristóteles, Kant, Bentham, Cobden. Elementos centrales en la visión liberal: interdependencia, anarquía que genera una demanda por cooperación, múltiples actores en la arena internacional, indivíduo. NOGUEIRA, João Pontes; MESSARI, Nizar, Teoria das Relações Internacionais...op. cit., pp. 58-62.

78 Ibídem, p. 60

79 SMOUTS, Marie-Claude (org.), As novas relações internacionais: práticas e teorias, UNB, Brasilia, 2004, p. 129
} 
limitara la injerencia a los asuntos nacionales, la no violación de los tratados, y evitar la guerra injusta. En ese sentido, aún no se pensaba en una institucionalización o en la creación de organismos permanentes, lo que existía era una antigua técnica de arbitraje, en la cual los estados emitían las reglas orientadas a asegurar la preservación de la soberanía ${ }^{80}$.

Más tarde, en el periodo de posguerra, la idea de cooperación se desarrolla en virtud del idealismo wilsoniano ${ }^{81}$, de una Sociedad de las Naciones, con el argumento central de que las instituciones podrían amoldar el comportamiento de los estados en la política internacional, y así evitar una nueva guerra. Este derecho de cooperación, consagrado por la creación del sistema de las Naciones Unidas (1945) e intensificado por la multiplicación de agencias especializadas y arreglos ad hoc ${ }^{82}$, amplió la noción de la regulación interestatal y pasó a favorecer la diplomacia multilateral ${ }^{83}$.

De este modo, la diplomacia multilateral se convirtió en una alternativa para que los representantes de los estados establecieran un diálogo para la discusión y resolución de los problemas comunes. En cuanto las reglas de conducta, el multilateralismo puede expresar una multiplicidad de arreglos que incluye organizaciones y regímenes globales/regionales o incluso alianzas militares y económicas.

En este contexto, para los fines de análisis de este estudio, las definiciones de organizaciones internacionales necesitan ser trabajadas, debido a la conexión que este campo posee para que pensemos al respecto de la efectividad de la protección internacional a los desplazados internos.

Por tanto, subrayamos que las Organizaciones Internacionales (OI) hacen parte de un conjunto mayor de instituciones que, de cierta manera, gestionan la gobernanza global ${ }^{84}$. Dentro de esta categoría, las Ol poseen, además del carácter permanente, un mayor grado de institucionalización frente a las demás formas de cooperación internacional, porque presentan un cuerpo burocrático, presupuestos regulares y espacio físico. De esta forma, se entiende que las $\mathrm{Ol}$ asumen un papel importante en la formulación de normas y procedimientos de conducta que son asimilados por los estados, debido al vínculo de participación que se establece entre sus miembros.

80 SMOUTS, Marie-Claude (org.), As novas relações internacionais...op. cit., p. I3।

81 El precursor de la búsqueda de un nuevo orden internacional después de la I Guerra Mundial fue el presidente norteamericano Woodrow Wilson. El propuso la creación de la Liga de las Naciones (1919) con la intención de crear un organismo destinado a la preservación de la paz y resolución de los conflictos internacionales. MARTIN, Lisa L.; SIMMONS, Beth A., "Theories and Empirical Studies of International Institutions" en International Organization, Cambridge, vol. 52, n 4, 1998, p. 729

${ }^{82}$ Se entiende por arreglos ad hoc los acuerdos que no poseen un carácter permanente, pueden ser reuniones de cúpula, conferencias y hasta cortes internacionales. Son criados para suplir una determinada demanda de las relaciones interestatales, cuando no hay un campo institucionalizado. Las agencias especializadas son entidades vinculadas a una organización mayor, como ocurre en el caso de las Naciones Unidas, donde hay una variedad de agencias actúan directa e indirectamente en determinadas áreas temáticas.Ver HERZ, Mônica; HOFFMANN, Andrea Ribeiro, Organizações internacionais: história e práticas, Elsevier, Rio de Janeiro, 2004, p. 21

83 MARTIN, Lisa L.; SIMMONS, Beth A.,"Theories and Empirical Studies...op. cit., p. 729

${ }^{84}$ En las palabras de Rosenau:"gobernanza no es lo mismo que gobierno. Mientras el gobierno sugiera actividades sustentadas por una autoridad formal, por el poder de policía que garantice la implementación de las políticas instituidas, la gobernanza se refiere a las actividades apoyadas en objetivos comunes, que pueden o no derivar de responsabilidades legales, y no dependen necesariamente del poder de policía para que sean aceptadas. En otras palabras, gobernanza es un fenómeno más amplio que incluye las instituciones gubernamentales, pero también los mecanismos informales de carácter no gubernamental". Ver ROSENAU, James Nathan, "Governança, ordem e transformação na política mundial" en BATH, Sérgio; ROSENAU, James Nathan; CZEMPIEL, Ernest-Otto, Governança sem governo: ordem e transformação na politica mundial, Imprensa Oficial do Estado, San Paulo, 2000, p. I5. 
Siguiendo esta lógica, Mitrany ${ }^{85}$ afirma que los estados solos no son capaces de controlar los fenómenos del sistema internacional, necesitan de una cooperación más eficiente, por medio de la cual entidades internacionales desempeñen funciones en el área técnica, dejando a cargo de los estados los asuntos políticos, como forma de reforzar la soberanía ${ }^{86}$. Por tanto, Mitrany ${ }^{87}$ ve a las Ol como un instrumento mitigador de conflictos de intereses, en virtud de su despolitización -teóricamente, son neutras y desempeñan actividades en el campo funcional-y por su potencial en ejercer la cooperación internacional canalizando la lealtad de las poblaciones.

Hay también otros autores como Barnett y Finnemore ${ }^{88}$, que definen las Ol como actores autónomos en la política mundial contemporánea, justificando que estas presentan dos características esenciales para ejercer influencia sobre los estados: la legitimidad de la autoridad racional-legal que encarnan en virtud de la producción de normas y reglas difundidas entre los estados; y el control de los conocimientos técnicos y de las informaciones. Estas dos fuentes proporcionan la base teórica para el tratamiento de las $\mathrm{Ol}$ como burocracias internacionales que producen efectos en el orden mundial, debido a la supuesta racionalidad en la realización de sus actividades.

Por otro lado, hay que tener en consideración que, como estas instituciones son oriundas de la propia voluntad de los estados, sus prácticas no están libres de los intereses egoístas de los estados, que producen barreras a las prácticas operacionales de las organizaciones. En este sentido, el estado actual de las cuestiones relacionadas a la protección de las PDI indica que, generalmente, las respuestas de las instituciones internacionales han sido inadecuadas en cuanto a la aplicación de las leyes internacionales y en cuanto a las actividades de protección y asistencia por parte de agencias responsables. Al final, la ONU y los demás organismos internacionales, se sienten aprisionados por una variedad de intereses de los estados, que rechazan dar protección y asistencia a los desplazados internos por diferentes razones - como, por ejemplo, una interpretación conservadora sobre el concepto de soberanía nacional- Siendo así, compartiremos la visión de Mitrany, Barnett y Finnemore para analizar la respuesta de las agencias internacionales al problema del desplazamiento forzado colombiano.

\section{La actuación de las instituciones internacionales en la atención a los desplazados internos en Colombia.}

Como ya se ha demostrado, a lo largo de su historia, Colombia ha convivido con el desplazamiento interno, hecho que intensificó la gravedad de las violaciones a los derechos de las PDI y, consecuentemente, exigió del estado una respuesta más proactiva y de emergencia para el enfrentamiento del problema. La respuesta del estado vino, pero en un momento tardío y de forma gradual. Eso porque, aunque la violencia generada por el conflicto armado ya hubiese impulsado el fenómeno de desplazamiento interno desde la década de 1980, el Estado colombiano

85 MITRANY, David, “The functional approach in historical perspective” en International Affairs, vol. 47, n 3, I97I, p. 534

86 Para Mitrany hay una fuerte tendencia en la política internacional por la autodeterminación y nacionalismo -los estados temen perder la soberanía y con eso existe el riesgo de que el interés nacional se sobreponga al interés público- de un lado, y de otro una demanda por cambios sociales — creación de políticas públicas más efectivas-. Entre estas dos tendencias se sitúan las Ol y su probable actuación en el campo técnico.Ver MITRANY, David,"The functional approach in historical...op. cit.

87 Ibídem, p. 537

${ }^{88}$ BARNETT, Michael N.; FINNEMORE, Martha,"The Politics, Power, and Pathologies of International Organizations" en International Organization, Cambridge, vol. 53, $n^{\circ} 4$, 1999, p. 707. 
solo comenzó a formular un cuerpo normativo dirigido al tratamiento de esta crisis a partir de los años $90^{89}$. Sin duda, las primeras iniciativas del gobierno correspondieron a la conjunción de los factores internos, por los graves efectos del desplazamiento, pero también al movimiento internacional que sintió la necesidad de proponer soluciones y prevenir el éxodo interno forzado, que llamaba la atención por su crecimiento progresivo.

La comunidad internacional por medio del Representante Especial del Secretario General para Desplazados Internos, advirtió para los efectos de la problemática que, por su complejidad, requería un abordaje más específico y especializado, de la cual derivó la redacción de los Principios Orientadores Relativos a los Desplazados Internos - PORDI.

Las iniciativas para la construcción de una cooperación con las agencias internacionales en Colombia ocurrieron en el marco de la promulgación de la Ley $n^{\circ} 387 / 97^{90}$ y de la elaboración de los PORDI, cuando el Estado colombiano buscó, en 1997, obtener la asistencia técnica de ACNUR, que ya poseía un mandato de actuación en el territorio en favor de la protección internacional de los refugiados desde 1996 en la atención a los desplazados internos. La propuesta de acción considerada por ambas partes, buscaba primordialmente reforzar las políticas del gobierno con el fin de administrar soluciones para el problema del desplazamiento interno y mejorar la situación de las víctimas de este fenómeno. En esta ocasión, la cooperación con ACNUR comprendía cinco líneas de actuación: I) acción preventiva; 2) protección y soluciones; 3) cumplimiento de la legislación interna; 4) fortalecimiento de los mecanismos de coordinación; 5) fortalecimiento de la cooperación internacional; 6) difusión y aplicación del Derecho Internacional Humanitario de los Refugiados ${ }^{91}$. Obsérvese que no había referencia a los PORDI, que todavía estaban en fase de aprobación por la Comisión de Derechos Humanos en 1998.

La instalación de la oficina de ACNUR en Bogotá — junio de 1998-, ocurrió en un periodo en el que los índices de desplazamiento interno colombiano se atenuaban continuamente, por eso la cooperación en esta área parecía ser necesaria. Aunque esta agencia de la ONU no hubiese sido creada particularmente para este fin, ya venía movilizando esfuerzos para responder a las situaciones de emergencia incluyendo a los desplazados internos, que presentaban muchas semejanzas en relación con los refugiados. De cualquier forma, su inserción puede ser considerada tardía - una vez que las altas cifras de PDI en Colombia comenzaron a emerger a partir de los años 80 con el recrudecimiento del conflicto armado- debido al retraso de la comunidad internacional en responder a esta problemática ${ }^{92}$.

De forma diferente aACNUR, el Comité Internacional de la Cruz Roja inició sus actividades

\footnotetext{
89 VIANA, Manuela Trindade, “Cooperação internacional e deslocamento interno...op. cit., p. I44

90 Primera acción del Estado colombiano en pro de los desplazados internos ocurrió por medio de la promulgación de la Ley $\mathrm{n}^{\circ} 387$ del 18 de julio de 1997 — por la cual se adoptaron "medidas para la prevención del desplazamiento forzado; la atención, protección, consolidación y estabilización socioeconómica de los desplazados internos por la violencia en la República de Colombia”. Ver CONGRESO DE LA REPÚBLICA DE COLOMBIA, Ley n 387, de 18 de julio de 1997:...op. cit.

91 ORGANIZACIÓN DE NACIONES UNIDAS,Alto Comissariado das Nações Unidas para os Refugiados - ACNUR, Memorando de intención entre la Oficina del Alto Comisionado de Naciones Unidas para los Refugiados (ACNUR) y el Gobierno de la República de Colombia, relativo al suministro de cooperación para el tratamiento del problema del desplazamiento forzado, 1999. Disponible en http://www.acnur. org/biblioteca/pdf/I530.pdf (consultado el I de Marzo de 2014), p. I

92 Es importante destacar que, hasta la instalación de la oficina de ACNUR en Colombia, el gobierno ya había enviado varias solicitudes a la agencia, que tardó en posicionarse en el caso.
} 
humanitarias tras la eclosión del conflicto en 1969, buscando actuar en el cumplimiento del Derecho Internacional Humanitario, tanto en la protección de los civiles como en la observación de las operaciones de las fuerzas armadas. En esta fase, el CICV actuaba en la asistencia a la población civil en general, sin dirigirse específicamente a los desplazados, hecho que ocurriera más tarde.

En efecto, se evidencia en este momento que las acciones de asistencia humanitaria dirigidas a los desplazados internos eran todavía modestas, pues les faltaba una dirección, o mejor, directrices que pudiesen ser utilizadas por las instituciones internacionales para planificar sus actividades de atención a las PDI. Por eso, fue solamente tras la redacción de los PORDI que las diferentes organizaciones de actuación en los campos de los derechos humanos y de la asistencia humanitaria, dentro y fuera del sistema de Naciones Unidas, pasaron a articularse mejor en la elaboración de las acciones de apoyo a los desplazados internos frente a las dificultades que enfrentan.

La percepción de que la asistencia humanitaria a las PDI requería esfuerzos en diferentes tipos de escenarios, como en el acceso a los servicios básicos, en la inclusión social, en la garantía de los derechos humanos y en la seguridad, llevó a los expertos de área a defender la tesis de que la respuesta internacional al problema del desplazamiento interno forzado debería estructurarse según el enfoque colaborativo, en el cual las agencias especializadas de la ONU y otras instituciones internacionales asumirían la responsabilidad conjunta de promover la protección a los desplazados ${ }^{93}$.

Se siguió entonces con que la creación del puesto de Coordinador de la Ayuda de Emergencia (ERC, por sus siglas en inglés) — también el Secretario General Adjunto de las Naciones Unidas para los Asuntos Humanitarios, cuya responsabilidad es promover iniciativas de protección y asistencia, movilizando apoyo político y financiero en situaciones de emergencia y de desastres naturales - y del Comité Permanente Interagencias (IASC, por sus siglas en inglés) - presidido por el ERC, principal instancia de coordinación y de toma de decisiones en relación a las asistencias humanitarias, reuniendo diferentes organismos, como la Organización Internacional de las Migraciones (OIM), el Relator Especial para los Derechos Humanos de los Desplazados Internos, el Comité Internacional de la Cruz Roja, entre otros- a mediados de los años 90, significó el medio para la coordinación de las acciones multidimensionales frente a las dificultades de los desplazados ${ }^{94}$.

Aunque esta estrategia demostrase, a primera vista, que los desplazados internos pudiesen recibir una cobertura más amplia de sus necesidades, esta acabaría por complejizarse dado que la diversidad de agentes internacionales en el tratamiento de la ayuda humanitaria por sus capacidades operacionales, especialidades y mandatos diferenciados, dificultaba su funcionalidad especialmente porque no había, en este proceso, una coordinación consistente y responsabilidades claramente

\footnotetext{
93 PONTHIEU, Aurélie; DERDERIAN; Katharine, “Respuestas humanitarias en el vacío de protección” en Revista Migraciones Forzadas, $\mathrm{n}^{\circ} 43$, 2013, p. 37.

94 ORGANIZACIÓN DE NACIONES UNIDAS, “Alto Comissariado das Nações Unidas para Refugiados - ACNUR: Grupo de trabalho do Grupo Setorial Global de Proteção”, Manual para la protección de los desplazados internos, 20 I0. Disponible en http://www.refworld.org/cgi-bin/ texis/vtx/rwmain/opendocpdf.pdf?reldoc=y\&docid=5I54I 9462 (consultado el 2 de Mayo de 20I3), p. 46.
} 
definidas entre las instituciones ${ }^{95}$.

Consecuentemente, en 2005 la ONU, identificando las lagunas causadas por esa forma de actuación especialmente en la protección de los desplazados internos, resolvió, por medio del IASC, promover una reestructuración en el enfoque de la respuesta humanitaria, que pasaría a adoptar un "enfoque de grupo sectorial”, más conocido como Cluster Approach".

Este abordaje tenía como objetivo implementar núcleos centrales y transversales para la asistencia humanitaria con la finalidad de fortalecer la colaboración entre los actores humanitarios, de derechos humanos y de desarrollo, tanto en el ámbito internacional como doméstico. El IASC acordó designar líderes de grupos sectoriales en nueve sectores o áreas de actividades globales que estaban poco cubiertas y carecían de un liderazgo en situaciones de emergencia humanitaria ${ }^{97}$. En la tabla I, abajo, se enumera la relación de los grupos sectoriales globales y los respectivos sectores, destacándose la categoría de los desplazados internos.

Tabla I - Cluster Approach - Grupos sectoriales globales

\begin{tabular}{|l|l|}
\hline SECTORY ÁREA DE ACTIVIDAD & LÍDER DELGRUPOSECTORIAL-NIVELMUNDIAL- \\
\hline Áreas técnicas & UNICEF \\
\hline I. Nutrición & OMS \\
\hline 2. Salud & UNICEF \\
\hline 3.Agua/Saneamiento & a) ACNUR \\
\hline $\begin{array}{l}\text { 4. Refugio de emergencia:a) PDI —conflicto- } \\
\text { b) situaciones de desastre }\end{array}$ & b) FICV \\
\hline Áreas transversales & a) ACNUR \\
\hline $\begin{array}{l}\text { 5. Coordinación y gestión de campos: a) PDI } \\
\text {-conflicto-; b) situaciones de desastre }\end{array}$ & b) OIM \\
\hline $\begin{array}{l}\text { 6. Protección: a) PDI —conflicto-; b) } \\
\text { situaciones de desastres/ otros civiles afectados } \\
\text { por conflictos }\end{array}$ & a) ACNUR \\
\hline 7. Recuperación inicial & b) ACNUR, OHCHR, UNICEF \\
\hline Áreas de servicios comunes & PNUD \\
\hline 8. Logística & \multicolumn{1}{|c|}{ PMA } \\
\hline 9. Comunicaciones de emergencia & OCHA, UNICEF, PMA \\
\hline
\end{tabular}

Fuente:Tabla adaptada por la autora del trabajo con base en las informaciones constantes en la Guía de Orientación del Cluster Approach por la Inter-Agency Standing Committee ${ }^{98}$.

\footnotetext{
95 PEDROSO, Ângela Maria Salvador, “A problemática dos deslocados internos: da natureza dos conflitos armados da actualidade às respostas da comunidade internacional”, Dissertação (Mestrado em Relações Internacionais) - Universidade Técnica de Lisboa, 20II. Disponible en https://www.repository.utl.pt/handle/l 0400.5/3828?mode=full (consultado el 17 de Marzo de 2014), p. 64.

${ }^{96}$ INTER-AGENCY STANDING COMMITTEE - IASC, Guía de orientación sobre el uso del enfoque de Grupo Sectorial ("Cluster Approach”) para fortelecer a respuesta humanitaria, Redhum: Red de Información Humanitaria para América Latina y el Caribe, Ciudad de Panamá, 2006. Disponible en http://www.redhum.org/documento_detail/470 (consultado el 01 de marzo de 2014), pp. I-2.

${ }_{97}$ Ibídem

${ }_{98}$ INTER-AGENCY STANDING COMMITTEE - IASC, Guía de orientación sobre el uso...op. cit., p. 3.
} 
Al evaluar la tabla I, observamos que el diseño de este nuevo abordaje añadió prominentemente la cuestión de los desplazados internos e involucró a ACNUR como principal agencia en el cuadro técnico y operacional de atención a las PDI que, en paralelo con otras organizaciones internacionales, pasó a actuar de manera proactiva en Colombia. En consecuencia, teniendo en cuenta la delimitación de nuestro objeto de estudio, pasaremos a la apreciación de la actuación de ACNUR y del CICV en Colombia, en el enfrentamiento de esta problemática, especialmente porque tanto ACNUR como la CICV prestan asistencia en materia de protección a los Derechos Humanos y al Derechos Internacional Humanitario respectivamente y, además, por ser organismos que desempeñan actividades humanitarias dirigidas, en especial, a las PDI por razones de conflicto armado, como es el caso colombiano.

En este sentido mediante el Cluster Approach, fue establecido en 2006 en Colombia un Equipo Humanitario para ofrecer una protección de grupo sectorial a las PDI, demoninada como Cluster de Proteción - Equipo Humanitario de Pais (CdP-EHP) que, teniendo a ACNUR como agencia líder, tenía como objetivo de forma coordinada identificar los vacíos y necesidades de protección y desarrollar estrategias de respuesta y prevención al desplazamiento interno, con el papel primordial de garantizar la ayuda correcta y la atención necesaria a las cuestiones transversales - como por ejemplo, salud y educación - en materia de asistencia humanitaria ${ }^{99}$.

En términos específicos, ACNUR trabaja, en este campo con cuatro líneas de acción: I. Difusión y actualización del marco legal de protección; 2 . Fortalecimiento de las políticas nacionales; 3. Capacitación y participación de la población desplazada en la defensa de sus derechos; y 4. Promoción de políticas públicas. Esas líneas de acción son empleadas en cooperación con otros actores, nacionales e internacionales ${ }^{100}$.

En este sentido, los principales interlocutores de ACNUR en Colombia son a nivel gubernamental: laAgencia Presidencial para la Acción Social y la Cooperación Internacional (Acción Social), la Defensoría del Pueblo y la Procuraduría General de la Nación; entre las organizaciones no gubernamentales: la Consultoría para los Derechos Humanos y Desplazamiento (CODHES), los Médicos Sin Fronteras, el Norwegian Refugee Council, la Secretaría de la Pastoral Social de la Iglesia Católica Colombiana y la Organización Nacional Indígena de Colombia; y en el ámbito internacional: el Comité Internacional de la Cruz Roja (CICV), el Fondo de las Naciones Unidas para la Infancia (UNICEF), el Programa de las Naciones Unidas para el Desarrollo (PNUD), la Oficina de las Naciones Unidas para la Coordinación de los Asuntos Humanitarios (OCHA, por sus siglas en inglés), la Oficina de las Naciones Unidas sobre Drogas y Crímenes (UNODOC), la Organización Internacional para las Migraciones (OIM) entre otras ${ }^{101}$.

En el ámbito de aplicación del Cluster Approach,ACNUR amplió el número de oficinas en Colombia a finales de 2006, a fin de promover una mejor integración en el trabajo con el gobierno y otras instituciones y, así, contribuir a la protección de las PDI en áreas que ya estaban recibiendo

\footnotetext{
99 GLOBAL PROTECTION CLUSTER, Términos de referencia: Cluster de Protección - Equipo Humanitario de País (CdP-EHP) 20II-20I2, 20I2. Disponible en file:///C:/Users/Priscila/Downloads/Colombia_PC_ToR_20II_20I2_ES.pdf (consultado el 0I de marzo de 2014), Pp. I-2.

100 VIANA, Manuela Trindade, “Cooperação internacional e deslocamento interno...op. cit., p. 151.

${ }^{101}$ ORGANIZACIÓN DE NACIONES UNIDAS, Alto Comissariado das Nações Unidas para os Refugiados - ACNUR. UNHCR Global Appeal 2013 Update - Colombia, 2012, pp. 276-280. Disponible en http://www.unhcr.org/50a9f83II6.html (consultado el 17 de Marzo de 2014), p. 279.
} 
ayuda humanitaria ${ }^{102}$. Tras el inicio de 2007 , y en referencia a los diez años de la Ley $n^{\circ} 387 / 97$, la agencia también lanzó una campaña, juntamente con la CODHES y la Iglesia Católica, sobre los Derechos de las Personas Desplazadas en la Colombia con la intención de sensibilizar al estado y a la comunidad internacional sobre la gravedad de la crisis del desplazamiento interno en el territorio, y de la incapacidad y falta de voluntad del gobierno en garantizar los derechos de las PDI ${ }^{103}$.

Más recientemente, ACNUR intentó desarrollar planes más amplios de atención a los casos de desplazamiento, y por eso intensificó sus acciones en las áreas de mayor concentración de PDI. En 20l I, la agencia asistió a cerca de cuatrocientos cuarenta mil desplazados del total de 3,9 millones contados por el gobierno, y realizó veintisiete campañas de registro en el SUR comprendiendo 21 estados y 104 municipios, contabilizando la emisión de ciento veintinueve mil trescientos certificados para los desplazados. Además, instaló cinco centros de acogida en las localidades de Puerto Leguízamo, Mocoa, Tame, Ipiales y Medellín, beneficiando a más de treinta y un mil personas y apoyó veintidos evaluaciones itinerantes - por actores internacionales, como el Refugee International-, con la participación de dos mil desplazados para la identificación de las necesidades y lagunas en su protección ${ }^{104}$.

En 20I2, el número de PDI auxiliadas por la agencia aumentó, sin representar una gran variación, hasta aproximadamente 460.000 . En dicho año, ACNUR se articuló con I 3 facultades de Derecho en Colombia para establecer clínicas de asistencia jurídica, principalmente con estudiantes de Derecho del último periodo con la finalidad de proporcionar a los desplazados internos consejos jurídicos y apoyo para beneficiarse de programas de asistencia del gobierno. Es importante señalar que estas clínicas llegaron a atender, solo en 2016, dos mil novecientos cuarenta y nueve casos. Además, la referida agencia de la ONU consiguió viabilizar acuerdos con otras cuatro facultades de psicología y servicio social para ofrecer atención psicológica para las víctimas de desplazamiento interno ${ }^{105}$.

Concerniente a la cooperación de ACNUR con la Acción Social, cabe destacar el proyecto Protección de Tierras y Patrimonio de la Población Desplazada — creado en 2003, con el respaldo del Fondo Posconflicto del Banco Mundial, de la Organización Internacional para las Migraciones, Agencia Española de Cooperación Internacional para el Desarrollo, entre otros- para promover la protección jurídica de los derechos de propiedad de las víctimas sobre las tierras de las cuales fueron despojadas forzadamente. Por medio de esa cooperación, en 2008, fueron protegidos 2,9 millones de hectáreas de tierras y ochocientos dieciocho edificios pertenecientes a las PDI en Colombia, localizados en 116 municipios. Actualmente, el proyecto opera continuamente en las localidades de Antioquia, Caribe —-Bolívar, Sucre, Magdalena, Atlántico y Córdoba-, GuajiraCesar, Centro -Bogotá, Meta y Cundinamarca—, Chocó, Magdalena Medio-Santander, Norte de

102 ORGANIZACIÓN DE NACIONES UNIDAS, Alto Comissariado das Nações Unidas para os Refugiados - ACNUR, "Working with the internally Displaced" en UNHCR, Global Report 2006, 2007, pp. 40-43. Disponible en http://www.unhcr.org/cgi-bin/texis/vtx/home/ opendocPDFViewer.html?docid=4a2fd85b6\&query=Working\%20with\%20the\%20internally\%20Displaced\%202006 (consultado el I2 de Marzo de 2014), p. 43

${ }^{103}$ ROMERO, Marco Alberto, “El año de los derechos de las personas desplazadas en Colombia” en Revista Migraciones Forzadas, $\mathrm{n}^{\circ} 29,2008, \mathrm{p} .58$.

104 ORGANIZACIÓN DE NACIONES UNIDAS, Alto Comissariado das Nações Unidas para os Refugiados - ACNUR, UNHCR Global Report 201 I - Colombia, 20I2, pp. 345-349. Disponible en http://www.unhcr.org/4fc880c0b.html (consultado el I7 de marzo de 20I4), pp. $346-347$.

105 ORGANIZACIÓN DE NACIONES UNIDAS, Alto Comissariado das Nações Unidas para os Refugiados - ACNUR, UNHCR Global Report 2012 - Colombia, 20I3. Disponible en http://www.unhcr.org/5 Ibl d646b.html (consultado el I7 de marzo de 20 I4), p. 2. 
Santander-Arauca, Tolima-Huila,Valle del Cauca-Cauca, Nariño y Putumayo, regiones que presentan altas cifras de desplazados ${ }^{106}$.

En el ámbito de la asistencia humanitaria encabezada por el $\mathrm{CICR}^{107}$ —que identificó en Colombia, en 20I2, cerca de ochocientas ochenta supuestas violaciones a las normas del Derecho Internacional Humanitario incluyendo entre ellas muertes, amenazas, desapariciones, reclutamiento forzado, violencia sexual, ataques contra la misión médica y el expresado desplazamiento interno-, una importante iniciativa fue la contribución en el traslado de los representantes de las FARC a Cuba, donde están teniendo lugar las conversaciones de paz con el gobierno. Por medio de ese subsidio, el CICV intenta llamar la atención a la protección de parte de la población que vive en las zonas de mayor conflicto y los otros civiles afectados, hasta entonces, por las acciones de los beligerantes ${ }^{108}$.

De manera general, la mayor parte de la asistencia del CICR a los desplazados internos colombianos, se concentra en la entrega de alimentos y utensilios domésticos básicos y de higiene personal, cobertura de gastos funerarios para las personas que perdieron un ser querido, entrega de material para la rehabilitación de infraestructuras y costeo de medicamentos y tratamientos médicos, especialmente en los lugares de difícil acceso, que reciben poca o ninguna asistencia del gobierno. Cabe mencionar que, la entrega de los alimentos a las PDI puede durar un periodo máximo de entre tres y seis meses, para las familias con especial vulnerabilidad ${ }^{109}$.

Es importante destacar que desde 1997, cuando fue iniciado el programa de Asistencia Humanitaria de Emergencia en Colombia dirigido a esta problemática, hasta 2017, el Comité consiguió atender a I 024940 personas —más de doscientas mil familias - teniendo, en los últimos cinco años, dirigido esfuerzos para el apoyo en comunidades indígenas (6\%) y afrocolombianas $(12 \%)^{110}$.

En esta ocasión, a fin de responder de manera adecuada a las necesidades de las PDI, el CICR comenzó a crear y a involucrarse en diferentes proyectos en Colombia, entre los cuales destacamos la creación del Programa de Distribución de Bonos (2005) "'l, desarrollado con el objetivo de proporcionar subsidio financiero para que los desplazados internos tengan la oportunidad de hacer sus compras en establecimientos comerciales próximos a su residencia, de acuerdo con su cultura de consumo. Esta iniciativa también fue pensada como una oportunidad para la integración de los desplazados a los procesos sociales y a la vida comunitaria en los lugares de llegada ${ }^{1 / 2}$.

\footnotetext{
106 UNIDAD PARA LA ATENCIÓNY REPARACIÓN INTEGRAL A LAS VíCTIMAS, Protección de Tierras y Patrimonio de la Población Desplazada, 20I3. Disponible en http://dpp.gov.co/contenido/contenido.aspx?catID=295\&conID=334I (consultado el 25 de Febrero de $20 \mathrm{I} 4$ )

${ }^{107}$ El CICV cuenta con 358 colaboradores en Colombia.

${ }^{108}$ COMITÉ INTERNACIONAL DE LA CRUZ ROJA - CICR, “Situación humanitria: informe de las atividades Colômbia 20I2”, 20I2. Disponible en http://www.icrc.org/spa/assets/files/20I3/colombia-report-20I2.pdf (consultado el 10 de Marzo de 20I4)

${ }^{109}$ OBERLI, Christina, Programa de asistencia del CICR a la población desplazada en Colombia, Comite Internacional de la Cruz Roja - CICR, 2007. Disponible en http://www.icrc.org/spa/resources/documents/feature/colombia-feature-290807.htm (consultado el I2 de marzo de 20I4)

${ }^{110}$ HINTERMANN, Barbara, El desplazamiento en Colombia, Comite Internacional de la Cruz Roja - CICR, 2007. Disponible en http://www.icrc. org/spa/resources/documents/feature/colombia-feature-290807.htm (consultado el 12 de Marzo de 20I4)

I" Programa implementado hasta el momento únicamente en el municipio de Bogotá

112 OBERLI, Christina, Programa de asistencia del CICR a la población...op. cit.
} 
En 20 I 2, el foco de atención a las PDI por la CICV fue dirigido a los casos de desplazamiento masivo quien, con apoyo de la Cruz Roja Colombiana, distribuyó ayuda humanitaria —alimentos, artículos de higiene y utensilios domésticos- a más de 16 mil personas en cuarenta y tres situaciones de desplazamiento en masa ${ }^{1 / 3}$. Un ejemplo de esta práctica ocurrió en la región de Cacua, donde el CICV se dirigió a la comunidad de Mango - una zona rural con apenas una vía de acceso y sin pavimentar, donde no había llegado ningún tipo de ayuda humanitaria- para auxiliar a la población desplazada —-mil quinientas persona-, que estaba prácticamente aislada, proporcionando catorce toneladas de suministros, además de materiales de construcción para la recuperación de las casas que fueron destruidas a causa de las confrontaciones entre grupos $\operatorname{armados}^{114}$.

Con el objetivo de prevenir el desplazamiento, el Comité desarrolla proyectos productivos en zonas de conflicto como la inversión en agropecuaria cuando las poblaciones afectadas por los confinamientos, por la falta de acceso seguro a los alimentos y contaminación por armas, pueden ser obligadas a desplazarse. En ese sentido, fueron promovidos incentivos al cultivo de cacao, maíz, plátano, arroz, y la cría de gallinas nativas e vacunación de caballos, de los cuales se beneficiaron mil quinientas cincuentas y tres familias en las localidades de Antioquia, Arauca, Cauca, Chocó, Guaviare, Nariño, Norte de Santander y Putumayo ${ }^{115}$.

En la dirección dada a las políticas gubernamentales, el CICV, atendiendo a las lagunas del Sistema de Registro Único de Víctimas (SUR), colaboró con las entidades del Ministerio Público en la organización de veinte jornadas para la consecución masiva de declaraciones para los desplazados, en los estados de Córdoba, Chocó,Valle, Putumayo y Nariño, que tuvieron como resultado la inscripción de doce mil cuatrocientas cuarenta y cinco personas, conforme prevé la Ley $n^{\circ} 387 / 97$. Además, el Comité hizo donaciones de ordenadores, impresoras y escáneres al Ministerio Público, a fin de contribuir en la aceleración del Registro Único de Víctimas ${ }^{116}$.

Por medio de esta explicación, intentamos demostrar cómo la comunidad internacional, a través de la actuación de las instituciones internacionales, ha buscado promover medios de atención y protección a los derechos humanos de las PDI en Colombia. Señalando para ello que, inicialmente, los mecanismos de asistencia humanitaria eran insuficientes para atender a las demandas de esa parte de la población, y por eso fue pensado un nuevo abordaje para el enfrentamiento de esta problemática, el Cluster Approach.

A partir de este nuevo enfoque, algunas organizaciones internacionales pasaron al tratamiento de casos de emergencia y de gran complejidad, como el desplazamiento interno, que por la ausencia de una agencia específica y de una coordinación de las actividades humanitarias prestadas por los actores internacionales, no conseguían llenar el vacío estatal. El caso de las PDI colombianas es emblemático en este sentido, por eso lo adoptamos como caso de estudio.

\footnotetext{
113 Todavía en 2012, el CICV también atendió más de 16 mil personas desplazadas individualmente. En el inicio de 2013, el Comité proporcionó asistencia a 1.099 personas desplazadas en casos individuales y masivos.

${ }^{114}$ COMITÉ INTERNACIONAL DE LA CRUZ ROJA - CICR, “Situación humanitaria...op. cit.

115 Ibidem

116 lbíd.
} 
Teniendo en consideración esta coyuntura, centralizamos nuestra demostración acerca de la actuación de las instituciones internacionales en la protección de los desplazados internos en Colombia, en ACNUR y CICV, con el fin de demostrar que la cooperación existente entre las diversas entidades, en el ámbito nacional e internacional es, especialmente en el enfrentamiento de este fenómeno, esencial para suplir las necesidades de las PDI.

\section{Obstáculos y limitaciones en la actuación de las Instituciones Internacionales en el contexto del desplazamiento interno colombiano.}

Habiendo alcanzado enorme proporción y continuidad en los últimos años y presentando todos los problemas señalados anteriormente, el desplazamiento interno colombiano se transformó en una crisis humanitaria que requería esfuerzos de las instituciones internacionales para establecer una cooperación, a fin de proporcionar medios para mitigar y solucionar esta problemática.

A lo largo del texto demostramos que, aunque tardíamente, la respuesta internacional produjo algunos efectos positivos para el tratamiento del desplazamiento interno, como la redacción de los PORDI. Estas, se volvieron una importante herramienta para la elaboración de los planes de acción de las instituciones internacionales que, a través de ellas, pasaron a actuar en razón de las vulnerabilidades específicas enfrentadas por los desplazados, incluyendo así desde la protección contra el desplazamiento hasta su término.

Sin embargo, aún pautadas en los PORDI, las estrategias adoptadas, en especial por las agencias humanitarias, son limitadas. La crítica dirigida a la comunidad internacional no se resume a la simple ausencia de un régimen vinculante para la protección de las PDI, pero también por la falta de una coordinación consistente de planificación de recursos insuficientes por parte de las instituciones internacionales que prestan asistencias a los desplazados.

El mayor problema de algunas Ols reside en el hecho de la falta de disposición de recursos financieros propios rápidamente accesibles. La ONU en particular, depende de la voluntad y donaciones de los estados-miembro para la obtención del capital necesario a la consecución de sus actividades en sus diversas ramas de actuación ${ }^{117}$. Por eso, los recursos utilizados en la asistencia humanitaria prestados por las agencias de la ONU en el caso colombiano, no son considerados satisfactorios una vez que al analizar los datos proporcionados por el Servicio de Acompañamiento Financiero (FTS-Financial Tracking Service) ${ }^{1 / 8}$, es posible constatar el bajo porcentaje designado por la Coordinación de Asuntos Humanitarios al estado, a través de los Fondos para la Respuesta de Emergencia (ERFs, por sus siglas en inglés).

El ERFs destinó entre 2012 y 2013 un valor estimado entre 3 y 4 millones de dólares, que equivale al porcentaje variante de entre el $7 \%$ y el $5 \%$ respectivamente del total de la ayuda humanitaria destinada a Colombia ${ }^{119}$, de los cuales el $28 \%$ fueron dirigidos a las víctimas del

\footnotetext{
17 BRANCO, Carlos Martins, “A ONU e o processo de resolução de conflitos: potencialidades e limitações” en Revista Relações Internacionais [Instituto Português de Relações Internacionais], n 5, 2004, p. 2

${ }^{118}$ Base de datos que registra toda la ayuda humanitaria proporcionada a los estados, incluyendo las donaciones de Organizaciones No Gubernamentales, de la CICV, bilaterales y particulares.

${ }^{119}$ En 2012, los ERFs asignaron el 83\% de los recursos para ONGs internacionales y el I7\% para la Red Nacional del Movimiento de la Cruz Roja.
} 
conflicto armado, y el $72 \%$ a los casos de desastre natural ${ }^{120}$. En el caso de ACNUR, la agencia empleó en 2012 cerca de veintiocho millones de dólares para atender a los desplazados internos, teniendo como resultado la asistencia de casi cuatrocientas sesenta mil personas.Aunque ACNUR tenga aumentado su atención en materia de desplazamiento interno, el porcentaje de PDI en Colombia asistidas por la agencia todavía puede ser evaluado como pequeño, equivaliendo al II,5\% del número de personas afectas por el problema apuntando por el IDMC en $2012^{12 !}$.

De este cuadro de recursos limitados, resulta un plan carente de soluciones a largo plazo. Conforme pudimos observar en los apuntes anteriores, tanto ACNUR como la CICV desarrollan proyectos de corta duración,y aún concentrados en las regiones de mayor intensidad del fenómeno, debemos tener en consideración que las entidades internacionales presentes en el territorio colombiano actúan en un ambiente hostil, en el que los beligerantes se muestran reacios a firmar acuerdos de paz, y donde la cuestión agraria, uno de los principales condicionantes del conflicto, permanece carente de una reforma y que, por eso, continúa lejos de ser resuelto debido al vínculo establecido con los grupos de narcotraficantes para el uso ilícito de la tierra en la producción de las drogas, lo que acaba dificultando la implementación de programas que busquen la estabilización de la población en estas zonas.

Además, necesitamos tomar nota de que Colombia, incluso inmersa en un conflicto interno, es vista como un estado relativamente fuerte que, por poseer un sistema político consolidado y mecanismos nacionales para atender los desplazados, aumenta las posibilidades de que las PDI vean sus derechos garantizados. Con todo, tanto en el contexto colombiano como en otros, pesa la cuestión de la soberanía ${ }^{122}$ que, especialmente en estados más fuertes, dificulta la participación y ampliación de las asistencias humanitarias. Una prueba de esto es que, en Colombia, las organizaciones humanitarias permanecen ejerciendo actividades similares o complementarias a las del gobierno nacional si, por eso, promover acciones que permitan el reajuste de las normas y políticas nacionales.

De forma diferente de Colombia, en estados vistos como más débiles, como por ejemplo Sudán y la República Democrática del Congo que también presentan víctimas de desplazamiento por razones de conflicto armado ${ }^{123}$, la comunidad internacional acaba encontrando más espacio para actuar debido a la inherente fragilidad interna, las débiles estructuras políticas, ausencia de voluntad política y un ordenamiento insatisfactorio dirigido a los desplazados internos, creando así una mayor relación de dependencia de estos con las agencias externas y con la ayuda humanitaria. Entre tanto, eso no quiere decir que, en estos casos, ellas sean más efectivas. De hecho, la asistencia en los estados mencionados, que ocurre por medio de intervenciones humanitarias, es

\footnotetext{
${ }^{20}$ ORGANIZACIÓN DE NACIONES UNIDAS, Office for the Coordination of Humanitarian Affairs - OCHA. Emergency Response Fund: Colombia - annual report 2012, 2013. Disponible en https://docs.unocha.org/sites/dms/Documents/2012\%20Annual\%20Report\%20 Colombia\%20ERF.pdf (consultado el2I mar. 20I4. (consultado el I 3 de noviembre de 20I3), p. 5

${ }^{121}$ Comprende 4,9 millones de PDI.

${ }^{122}$ No pretendemos entrar en los debates acerca del concepto de soberanía y de la cuestión de la inviolabilidad de los territorios — sabiendo que se refiere a un asunto controversial y polémico- ya que nuestro estudio no se dirige hacia una discusión en este plano teórico. Sin embargo, es cierto que los estados se valen de este principio cuando se sienten amenazados por otros estados y cuando van a recibir cualquier tipo de asistencia humanitaria. OLIVEIRA, Ariana Bazzano. "Resenha: Intervenções humanitárias - a tensão entre os direitos humanos e a soberania" en Carta Internacional, vol. 4, $\mathrm{n}^{\circ}$ 2, 2009, pp. II7.

${ }^{123} \mathrm{~A}$ pesar de que cada uno de estos estados presenten conflictos internos con dinámicas diferenciadas, la mayor parte de los desplazamientos ocurre en virtud del elevado grado de inseguridad y violencia dirigida a los civiles.
} 
decir, de acciones que van más allá de la protección en materia de Derechos Humanos, incluye también operaciones de paz, estabilización y reconstrucción política, social y económica.Así, acaba a veces concentrándose más en las operaciones de paz y enfrentando problemas similares a los de Colombia - como la falta de recursos y planificaciones insuficientes para el corto plazo.

En alguno de estos contextos, existe también la noción de que los principios de la neutralidad e independencia de los agentes humanitarios están cada vez más frágiles, ante las poblaciones que ven a los trabajadores humanitarios más como personas que persiguen objetivos políticos por medio de una asistencia parcial y politizada, que por acciones neutras dirigidas exclusivamente para ayudar a los más vulnerables ${ }^{124}$.

En el caso colombiano, la estrecha integración de esas organizaciones con los proyectos desarrollados por el gobierno - uno de los agentes que contribuyen para el desplazamiento interno - traslada la imagen de que estas están más alineadas a la política nacional diseñada por el estado, que empeñadas en obtener respuestas pragmáticas para atender las dificultades concretas enfrentadas por las víctimas del desplazamiento.

Vinculado a esas cuestiones, la falta de coordinación consistente entre las instituciones internacionales pesó negativamente en la protección de los desplazados internos. Hasta que fuese pensada una forma de organizarse y coordinar la asistencia humanitaria de la ONU para el tratamiento de áreas complejas, como el del desplazamiento interno, ACNUR permaneció operando en Colombia sin mucho compromiso con los desplazados internos, teniendo en consideración que fue creada para asistir a los refugiados. Así, la agencia acabó actuando entre finales de los años 90 y mediados de 2005, de forma secundaria en la protección de las PDI y limitándose en proporcionar apoyo técnico a los programas del gobierno.

Se continuó entonces con que la reforma humanitaria introducida en la ONU terminaría respaldando sobre ACNUR de manera preponderante y alcanzando los casos de desplazamiento interno. En poco tiempo, el proyecto amplio y audaz propuesto por el IASC, pasó a funcionar en Colombia y produjo algunos avances especialmente a través de ACNUR que amplió su presencia en el territorio con la instalación de nuevas oficinas y pasó también a atender un mayor número de PDI ${ }^{125}$.Además, ampliaría su abanico de cooperación, pasando a colaborar con otras instituciones internacionales y nacionales conforme señalamos anteriormente, como por ejemplo las ONGs ${ }^{126}$.

Sin embargo, aun habiendo obtenido algunos resultados, los cambios que provienen de esta reforma caminan a pasos lentos o, mejor dicho, sin producir grandes efectos para los desplazados internos en Colombia. El hecho es que permanece la ausencia de datos claros acerca de este fenómeno en el ámbito interno de los estados, particularmente en Colombia, en el cual es evidente que la política de evaluación empleada por el gobierno presenta fallos estructurales que, hasta el momento, no han recibido la debida atención por las agencias de la ONU —en especial

\footnotetext{
124 STOBBAERTS, Eric; MARTIN, Sarah; DERDERIAN, Katharine, “Integración y reforma humanitarian” en Revista Migraciones Forzadas, $\mathrm{n}^{\circ} 29$. 2008, pp. 18-20, p. 20

125 Mientras que en 2005 fueron asistidos 260mil PDI por ACNUR, en 2012 ese número llegó a 460 mil personas.

${ }^{126}$ De acuerdo con Ferris, ACNUR realiza la mayor parte de su trabajo a través de las ONGs. En 2007, fueron firmados 550 acuerdos con 420 ONGs nacionales y 417 con I5I ONGs internacionales.Ver FERRIS, Elizabeth, "La Plataforma Humanitaria Global: ¿una oportunidad para las ONG? Reforma Humanitaria: ipromesas cumplidas?” en Revista Migraciones Forzadas, Alicante [Universidad de Alicante], n 29,2008, p. 7.
} 
ACNUR-, ocasionando un contrasentido entre las estimaciones nacionales e internacionales, dificultando aún más la planificación de prevención y protección a los desplazados internos.

Hasta el momento, no se ha demostrado que la actuación de ACNUR dirigida a los desplazados internos haya afectado su mandato especial en relación a los refugiados, no obstante, por más que la agencia haya adoptado como una de sus líneas principales la atención a los desplazados internos, aún permanece carente de un mejor desempeño en Colombia como agencia líder, ya que ella actúa más paralelamente a los proyectos de las demás instituciones humanitarias y del gobierno, que a través de un programa unificado de acción. Por eso, una cuestión parece clara: la complejidad del fenómeno del desplazamiento interno demanda una mayor implicación de la agencia en su proceso de coordinación y, por eso, es necesario adoptar un proceso unificado en colaboración con las diversas agencias humanitarias en el territorio para la obtención de informaciones cuantitativas y cualitativas del fenómeno, a fin de facilitar la formulación de las actividades humanitarias y asignar los recursos más adecuados para abarcar mejor las vulnerabilidades de los desplazados.

Así, la respuesta de la comunidad internacional a las necesidades de las PDI continúa siendo selectiva y negligente. Selectiva porque, como los recursos son escasos y las capacidades limitadas, las instituciones escogen las situaciones con las cuales irán a actuar, dependiendo de sus mandatos, de sus prioridades, intereses políticos, del capital financiero y del contingente disponible, volviéndose así descoordinada e inconsistente. Negligente, porque presente fallos en los planos de acción dirigidos a suplir las necesidades de los desplazados, particularmente en los que se refiere a las medidas de largo plazo, como educación y desarrollo socioeconómico, la prevención y al retorno/reintegración de los desplazados al local de origen ${ }^{127}$.

\section{Conclusión}

La concepción de este estudio tuvo lugar en medio de las violaciones de los Derechos Humanos en Colombia, más precisamente, a los casos de violaciones contra los desplazados internos. Partiendo de esa coyuntura, el presente artículo tuvo como objetivo identificar las políticas y los desafíos referentes a la protección internacional de los derechos humanos en el campo de actuación de las Instituciones Internacionales en el país.

En ese sentido, intentamos demostrar que la protección internacional a los desplazados internos en Colombia es necesaria pero todavía limitada, teniendo en consideración que persiste el cuadro de intensa vulnerabilidad de los desplazados, incluso con la asistencia humanitaria proporcionada por las agencias y organizaciones internacionales, y que esa realidad resulta principalmente, de los fallos en el plan de efectuación de las acciones humanitarias. Grupos armados ilegales permanecen activos y violan una amplia gama de derechos humanos. Cerca de 139.000 nuevos desplazamientos debido a conflictos y violencia fueron registrados en 2017 . Además, desastres de inicios súbitos y adquisiciones de tierras en gran escala para proyectos de desarrollo han aumentado la complejidad del desplazamiento en el país.

Constatamos que el desplazamiento interno colombiano resulta predominantemente de la

${ }^{127}$ TIMO, Pétalla Brandão, “Quando o doméstico é internacional: a problemática do deslocamento interno de pessoas” en Revista Cadernos de Relações Internacionais, vol. 2, $n^{\circ} 2,2009$, p. 16 
onda de violencia e inseguridad, instaurada como consecuencia del conflicto interno. La dinámica continua del conflicto, caracterizada por la multiplicidad de actores, sesgada por luchas ideológicas y amenazas de organizaciones criminales, se transubstanció en acciones deliberadas - por parte de las guerrillas, paramilitares y fuerzas nacionales - contra la población civil. Los constantes asesinatos, los secuestros, la extorsión, las intimidaciones, las expropiaciones de tierra, destrucción de poblados, reclutamiento forzado, aliados a un estado omiso e incapaz, contribuyeron a que innúmeras personas fuesen obligadas a desplazarse a otras regiones.

A pesar de afirmar que las disputas, amenazas y violencia debidas al conflicto armado colombiano son las grandes propulsoras del desplazamiento interno, destacamos también que factores como la disputa por territorios, tierras y motivaciones sociales y económicas, como la participación de grupos económicos y de los narcotraficantes actuando en pro de la manutención y explotación de la tierra por medios ilegales, también hacen parte de las causas que llevaron tanto a la intensificación del conflicto como el aumento de la pérdida de raíces de la población.

De la misma forma, constatamos la amplitud y continuidad expresiva del desplazamiento interno en Colombia. Sus dimensiones confirman los datos que colocan el estado en primer lugar en el último ranking publicado por el IDMC acerca de las PDI en el mundo. Se subrayan que los desplazamientos ocurren tanto colectivamente como de forma individual, presentando este último las mayores cifras, con la mayor parte de las expulsiones registrados en las zonas rurales - debido a que el dominio ejercido por los grupos armados y por ser regiones con abundantes recursos naturales-, y más recientemente en áreas intraurbanas.

Aclaramos que la comunidad internacional, especialmente la ONU, en la búsqueda de caminos para enfrentar la compleja realidad del desplazamiento interno, buscó una forma de enfrentar esta problemática por medio del enfoque de grupo sectorial. Ese abordaje elaborado con la intención de atender casos como el de desplazamiento interno, que no poseen un documento vinculante, ni agencia específica en el tratamiento de esta materia, permitió en el corto plazo que ACNUR, agencia responsable de la coordinación sectorial, pudiese expandir su foco de actuación y aumentase sus iniciativas en el territorio colombiano.

Sin embargo, aun habiendo obtenido algunos resultados, este enfoque todavía no ha tenido grandes efectos para los desplazados internos en Colombia. Por eso, evidenciamos que la protección internacional a los desplazados internos colombianos es limitada y presenta fallos porque, en primer lugar, ACNUR todavía no consiguió desarrollar una coordinación más consistente, $y$ las agencias humanitarias no poseen una planificación ni recursos suficientes para cubrir el plan de acción para las asistencias prestadas a los desplazados; y segundo, por la falta de compromiso de la comunidad internacional, especialmente de la ONU que se enfrenta a obstáculos como la dependencia a los recursos financieros derivados de los estados-miembro y la dificultad de mantenerse como entidad imparcial y neutra.

Frente a este contexto, verificamos que hay un largo camino por recorrer en materia de protección a los derechos humanos de los desplazados internos, no solo por parte del estado, sino también por las instituciones internacionales. En primer lugar, confirmamos nuestra hipótesis de que la protección internacional a los desplazados internos en Colombia es limitada y presenta 
muchos fallos, teniendo en consideración que ACNUR todavía no consiguió desarrollar una coordinación más consistente y porque las agencias humanitarias no poseen una planificación y recursos suficientes para cubrir el plano de acción para las asistencias prestadas a los desplazados.

En segundo lugar, constatamos que, aun no siendo un régimen vinculante, los PORDI fueron interiorizados por Colombia produciendo avances en materia de normalizaciones para la protección de las PDI, y asimilados por las instituciones internacionales propiciando programas que busquen la protección de las víctimas afectadas por el desplazamiento. Sin embargo, así como el estado, las agencias y organizaciones internacionales no lograron recibir asistencia humanitaria de acuerdo con las de las tres esferas de atención a los desplazados internos, descuidando particularmente los campos de la prevención y de la protección tras la finalización del desplazamiento.

Por último, entendemos que las lagunas en la protección de las PDI existen no por la ausencia de normas, sino por la falta de voluntad e intereses de los gobernantes en ponerlas en práctica por los interventores que surgen inherentemente del conflicto interno y de la compleja red de actores incluidos en las formas de violencia perpetradas contra la población civil por problemas estructurales como la cuestión agraria y por la falta de compromiso de la comunidad internacional, que tardó en buscar respuestas para esta problemática, especialmente la ONU que enfrenta obstáculos como la dependencia de los recursos financieros derivados de los estados miembro y la dificultad de mantenerse como una entidad imparcial y neutra. Lo que significa decir que no hay una coordinación clara y consistente entre las agencias y organizaciones internacionales en actuación en Colombia, por la falta de recursos y planificaciones insuficientes, y por ser selectiva y negligente.

Bibliografía

BAGLEY, Bruce Michael,“Narcotráfico, violencia política y política exterior de Estados Unidos hacia Colombia en los noventa" en Revista Colombia Internacional, $n^{\circ}$ 49-50, 2000, pp. 05-38.

BARNETT, Michael N.; FINNEMORE, Martha, “The Politics, Power, and Pathologies of International Organizations” en International Organization, Cambridge, vol. 53, ${ }^{\circ}$ 4, 1999, pp. 699-732.

BRANCO, Carlos Martins, “A ONU e o processo de resolução de conflitos: potencialidades e limitações” en Revista Relações Internacionais, $\mathrm{n}^{\circ}$ 5, 2004, p. 19.

CASTLES, Stephen, "International migration at the beginning of the twenty-first century: global trends and issues" en International Social Sciences Journal, vol. 52, n 165, 2002, pp. 269-28I.

CASTLES, Stephen, “The International Politics of Forced Migration" en Development, vol. 46, n 3, 2003, pp. II-20. Disponible en http://econpapers.repec.org/article/paldevelp/ v_3a46_3ay_3a2003_3ai_3a3_3ap_3all-20. htm (consultado el 25 de Mayo de 2013)

CENTRO NACIONAL DE MEMORIA HISTÓRICA,“;Basta ya!:Colombia - memorias de guerra y dignidad”, Imprenta Nacional, Bogotá, 2013.

COHEN, Roberta,"The Guiding Principles on Internal Displacement: a new instrument for international organizations and NGOs" en Forced Migration Review, 1998, pp. 31-33.

COHEN, Roberta; DENG, Francis Manding, "Orígenes y desafíos" en Revista Migraciones Forzadas: Alicante, Diez años de los principios rectores del desplazamiento interno, 2008, pp. 04-05.

CONGRESO DE LA REPÚBLICA DE COLOMBIA, Ley $n^{\circ}$ 387, de 18 de julio de 1997: por la cual se adoptan medidas para la prevención del desplazamiento forzado; la atención, protección, consolidación y estabilización socioeconómica de los desplazados internos por la violencia en la República de Colombia", 1997. Disponible en http://www.unhcr.org/refworld/docid/3dbd4c6b5.html (consultado el 25 de febrero de 2014)

DEFENSORÍA DEL PUEBLO DE COLOMBIA, COORDINACIÓN DE ATENCIÓN AL DESPLAZAMIENTO FORZADO, Persistencia del desplazamiento forzado interno em Colombia: dinámica del desplazamiento forzado, Defensoría del Pueblo, Colombia, 20Il. Disponible en http://www.defensoria.org.co/red/index.php? item $=||$ 0507\&_secc $=||$ \&ts $=2 \&$ hs $=|| 105$ (consultado el 24 de Enero de 20|4)

COMITÉ INTERNACIONAL DE LA CRUZ ROJA - CICR,"Situación humanitria: informe de las atividades Colômbia 
20I2", 20I2. Disponible en http://www.icrc.org/spa/assets/files/20I3/colombia-report-20I2.pdf (consultado el 10 de Marzo de 20I4)

COMITÉ INTERNACIONAL DE LA CRUZ ROJA - CICR, "Violência e o uso da força”, 2009. Disponible en http:// www.icrc.org/por/assets/files/other/icrc_007_0943.pdf (consultado el 23 de junio de 20I3).

CONSULTORÍA PARA LOS DERECHOS HUMĀNOS̄Y EL DESPLAZAMIENTO - CODHES, "La crisis humanitaria en Colombia persiste: el Pacífico em disputa - informe de desplazamiento forzado" en Documentos CODHES, $\mathrm{n}^{\circ}$ 26, 2013. Disponible en http://www.Iwfcolombia.org.co/sites/default/files/image/310513\%20Informe\%20 \%20desplazamiento\%2020I2.pdf (consultado el I0 de enero de 20I4)

COMISIÓN DE SEGUIMIENTO A LA POLÍTICA PÚBLICA SOBRE EL DESPLAZAMIENTO FORZADO, Tercer informe de verificación sobre el cumplimento de derechos de la población en situatión de desplazamento, CODHES, Bogotá, 2010.

CORPORATIÓN NUEVO ARCO IRIS, Breve história do conflito armado colombiano e os seus atores, 20I2. Disponible en http://prezi.com/hsxcazyskpsa/copy-of-breve-historia-do-conflito-armado-colombiano-e-os-seus-atores/ (consultado el I5 de Enero de 20I4)

CRAVINHO, João Gomes, "Visões do mundo: as relações internacionais e o mundo contemporâneo", Imprensa de Ciências Sociais, Lisboa, 2006.

CUNHA, Guilherme da, “Migrantes e refugiados: marco jurídico e estratégia no limiar do século XXI” en PINHEIRO, Paulo Sérgio; GUIMARÃES, Samuel Pinheiro (orgs), Direitos humanos no século XXI, IPRI/ FUNAG, Brasilia, 2002.

DARIO, Diogo Monteiro, “As Populações Internamente Deslocadas pelo conflito colombiano durante o governo Uribe: uma reflexão sobre os usos da segurança humana na era da Guerra contra o Terror”, Dissertação (Mestrado em Relações Internacionais) - Pontifícia Universidade Católica do Rio de Janeiro, Rio de Janeiro, 2009. Disponible en http://www.maxwell.lambda.ele.puc-rio.br/I4094/I4094_I.PDF (consultado el 23 de junio de 20I3)

DUQUE, Karol Vanessa Ramirez, "Análise espacial do deslocamento forçado na Colômbia por causa do conflito armado interno”, Dissertação (Mestrado em Geografia Humana) - Universidade de São Paulo, San Paulo, 2017. Disponible en http://www.teses.usp.br/teses/disponiveis/8/8136/tde-07022018-10324l/es.php (consultado el 21 de Febrero de 2019)

ESTRADA, A. J., "Orden neoliberal y reformas estructurales en la década del 90. Un balance desde la experiencia colombiana" en Revista Ciencia política, UNAL, n I, 2006, pp. I4 I-I 78.

FARJADO, D., “Comisión Histórica del Conflicto y sus Víctimas”, Reporte: Contribución al entendimiento del conflicto armado en Colombia, Imprenta Nacional, Bogotá, 2015.

FELBAB-BROWN, Vanda, "Shooting up: the impacto of illicit economies on military conflicto" en Massachusetts Institute of Technology, vol. 2, 2006, p. 640. Disponible en http://hdl.handle.net/I72I.I/38600 (consultado el 2 I de Noviembre de 2018)

FERRIS, Elizabeth, "La Plataforma Humanitaria Global: ¿una oportunidad para las ONG? Reforma Humanitaria: ipromesas cumplidas?” en Revista Migraciones Forzadas, Alicante [Universidad de Alicante], n² 29, 2008, PP. 06-08.

FRANCO, Andrés, "Los desplazamientos internos en Colombia: una conceptualización política para el logro de soluciones de largo plazo" en Revista Colombia Internacional, $\mathrm{n}^{\circ} 42$, 1998, pp. 05-26.

FREITAS, Pedro Jorge de, “América Latina em Guerra” en Revista Leituras da História, n 12, 2008.

GLOBAL DATABASE, Guiding Principles on Internal Displacement: The guiding principles: Introduction to the guiding principles", 20I3. Disponible en http://www.idpguidingprinciples.org/ (consultado el 24 de Mayo de 2013)

GLOBAL PROTECTION CLUSTER, Términos de referencia: Cluster de Protección - Equipo Humanitario de País (CdP-EHP) 20I I-20I2, 20I2. Disponible en file:///C:/Users/Priscila/Downloads/Colombia_PC_ToR_20II_20I2_ES.pdf (consultado el 01 de Marzo de 20I4)

GUTIÉRREZ, F.; PEÑARANDA, D., Mercados y armas: conflicto armado y paz en el periodo neoliberal: Latina America, una evolución, IEPRI, Revista La Carreta, Medellín, 2009.

HAAS, Peter M., "Introduction: Epistemic communities and international policy coordination" en International Organization, Cambridge, vol. 46, n I, 1992, pp. I-35.

HERZ, Mônica; HOFFMANN, Andrea Ribeiro, Organizações internacionais: história e práticas, Elsevier, Rio de Janeiro, 2004.

HINTERMANN, Barbara, El desplazamiento en Colombia, Comite Internacional de la Cruz Roja - CICR, 2007.Disponible en http://www.icrc.org/spa/resources/documents/feature/colombia-feature-290807.htm (consultado el 12 de Marzo de 20I4)

HUMAN RIGHTS WATCH, The risk of returning home: violence and threats against displaced people reclaiming land in Colombia, Human Rights Watch, USA, 2013. Disponible en https:/www.hrw.org/report/2013/09/17/ risk-returning-home/violence-and-threats-against-displaced-people-reclaiming-land (consultado el 10 de Diciembre de 2018)

INÁCIO, César Dutra, "Conflito armado na Colômbia" en Revista Eletrônica Boletim do tempo, vol. 6, n I9, 201 I. Disponible en http://tempo.tempopresente.org/index.php?option=com_content\&view=article\&id=2437:co nflito-armado-na-colombia\&catid=207\&lang=es (consultado el 10 de Diciembre de 20I8)

INTER-AGENCY STANDING COMMITTEE - IASC, Guía de orientación sobre el uso del enfoque de Grupo Sectorial 
(“Cluster Approach”) para fortelecer a respuesta humanitaria, Redhum: Red de Información Humanitaria para América Latina y el Caribe, Ciudad de Panamá, 2006. Disponible en http://www.redhum.org/documento_ detail/470 (consultado el 01 de Marzo de 2014)

INTERNAL DISPLACEMENT MONITORING CENTRE - IDMC, Global Reporto $n$ Internal Displacement (GRID 20I8). Conflict displacement Figures analysis. Disponible en http://www.internal-displacement.org/sites/default/ files/20I8-05/GRID\%202018\%20-\%20Figure\%20Analysis\%20-\%20COLOMBIA.pdf (consultado el 08 de Diciembre de 2013)

INTERNAL DISPLACEMENT MONITORING CENTRE - IDMC, Global IDP estimates (I990-20 I I), 20 I I. Disponible en http://www.internaldisplacement.org/8025708F004CE90B/(httpPages)/I0C43F54DA2C34A7CI2573A I 004EF9FF?OpenDocument (consultado el 13 de Noviembre de 2013)

INTERNAL DISPLACEMENT MONITORING CENTRE - IDMC, Colombia: property restitution in sight but integration still distant, Norwegian Refugee Council, Ginebra, $201 \mathrm{I}$.

INTERNAL DISPLACEMENT MONITORING CENTRE - IDMC, Global overview 20I I: people internally displaced by conflict and violence, Norwegian Refugee Council, Ginebra, 2012.

INTERNAL DISPLACEMENT MONITORING CENTRE - IDMC, Global Overview 20 I 2: People internally displaced by conflict and violence, Norwegian Refugee Council, Ginebra, 2013.

INTERNAL DISPLACEMENT MONITORING CENTRE - IDMC, Who is an Internally Displaced Person? Training on the Protection of IDPs, 2005. Disponible en http://www.internal-displacement.org/802570F8004C0A58/ (httpPages)/27E7C556E3549FC8802570A 10047IF33?OpenDocument (consultado el I 3 de Noviembre de 20I3)

INTERNAL DISPLACEMENT MONITORING CENTRE - IDMC, Para que se sepa: hablan las personas desplazadas en Colombia, 2007, pp. 93-100. Disponible en http://www.acnur.org/biblioteca/pdf/5 I57.pdf?view=I (consultado el I5 de Marzo 20I4)

INTERNATIONAL CRISIS GROUP, Colombia's FARC Conflict. Internactive Presentations, 2009. Disponible en https://www. crisisgroup.org/latin-america-caribbean/andes/colombia/interactive-colombias-farc-conflict (consultado el 10 de Diciembre de 2018)

JANSEN, Clifford, “Some sociological aspects of migration” en JACKSON, John Archer (coord.), Migration, Cambridge University Press, Cambridge, 1969, pp. 60-73.

KALIN,Walter; KÜNZLI, Jörg, The law of international human rights protection, Oxford University Press, Oxford, 2009.

KURTENBACH, Sabrine, Europe and the Colombian Conflict. Inter-American Dialogue, 2005. Disponible en http://archive. thedialogue.org/PublicationFiles/Europe\%20and\%20Colombia,\%20Kurtenbach\%20(June\%202005).pdf (consultado el 12 de Diciembre de 2018)

MARTIN, Lisa L.; SIMMONS, Beth A., "Theories and Empirical Studies of International Institutions" en International Organization, Cambridge, vol. 52, n 4, 1998, pp. 729-757.

MAZÓN, Ann, "La crisis de seguridad en Colombia: causas y consecuencias internacionales de un estado en vía de fracas" en Revista Colombia Internacional, n 49-50, 2000, pp. 82-102.

MITRANY, David, "The functional approach in historical perspective" en International Affairs, vol. 47, n' 3, I97I, PP. $532-543$

MOLINA, G., Las ideas socialistas en Colombia, Tercer Mundo Editores, Bogotá, 1988.

MURCIA, Luis Eduardo Pérez. "Desplazamiento forzado en Colombia 1995-1999: una aproximación empírica a las relaciones entre desplazamiento, conflicto armado y desarrollo” en SUÁREZ, Hernán (ed.), El Desplazamiento forzado en Colombia: compromisos desde la universidad, Asociación Colombiana de Universidades - ASCUN e CODHES, Bogotá, 2002, pp. I7-88.

NOGUEIRA, João Pontes; MESSARI, Nizar, Teoria das Relações Internacionais: correntes e debates, Campus - Elsevier, Rio de Janeiro, 2005.

NORWEGIAN REFUGEE COUNCIL - NRC, Internally displaced people: a global survey, IDMC, USA, 2002.

OBERLI, Christina, Programa de asistencia del CICR a la población desplazada en Colombia, Comite Internacional de la Cruz Roja - CICR, 2007. Disponible en http://www.icrc.org/spa/resources/documents/feature/colombiafeature-290807.htm (consultado el 12 de Marzo de 20I4)

OLIVEIRA,Ariana Bazzano. "Resenha: Intervenções humanitárias - a tensão entre os direitos humanos e a soberania" en Carta Internacional, vol. 4, $n^{\circ}$ 2, 2009, pp. II7-I2I.

OLIVEIRA, Eduardo Cançado. "A proteção jurídica internacional dos deslocados internos" en Revista do Instituto Brasileiro de Direitos Humanos, vol. 5, n 5, 2004, pp. 73-92.

ORGANIZACIÓN DE NACIONES UNIDAS, Alto Comissariado das Nações Unidas para os Refugiados - ACNUR, Tendencias Globales: desplazamiento forzado en 2017". Disponible en https://www.acnur.org/5b2956a04.pdf (consultado el 9 de Diciembre de 2018)

ORGANIZACIÓN DE NACIONES UNIDAS, Alto Comissariado das Nações Unidas para Refugiados - ACNUR, Who we help: internally displaced people: On the run in their own land, 2013. Disponible en http://www.unhcr.org/ pages/49c3646c|46.html (consultado el 22 de Mayo de 2013)

ORGANIZACIÓN DE NACIONES UNIDAS, Office for the Coordination of Humanitarian Affairs - OCHA Emergency Response Fund: Colombia - annual report 2012, 2013. Disponible en https://docs.unocha.org/ sites/dms/Documents/2012\%20Annual\%20Report\%20Colombia\%20ERF.pdf (consultado el2I mar. 2014. (consultado el 13 de Noviembre de 2013) 
ORGANIZACIÓN DE NACIONES UNIDAS, Alto Comissariado das Nações Unidas para os Refugiados - ACNUR, UNHCR Global Report 2012 - Colombia, 20 I 3. Disponible en http://www.unhcr.org/5 I b I d646b.html (consultado el 17 de Marzo de 2014)

ORGANIZACIÓN DE NACIONES UNIDAS, Office for the Coordination of Humanitarian Affairs - OCHA Emergency Response Fund: Colombia - annual report 2012, 2013. Disponible en https://docs.unocha.org/ sites/dms/Documents/2012\%20Annual\%20Report\%20Colombia\%20ERF.pdf (consultado el2I mar. 20I4. (consultado el 13 de Noviembre de 20I3)

ORGANIZACIÓN DE NACIONES UNIDAS, Alto Comissariado das Nações Unidas para os Refugiados - ACNUR. UNHCR Global Appeal 2013 Update - Colombia, 2012, pp. 276-280. Disponible en http://www.unhcr. org/50a9f83 I I6.html (consultado el I7 de Marzo de 20I4)

ORGANIZACIÓN DE NACIONES UNIDAS, Alto Comissário das Nações Unidas para Refugiados - ACNUR, Situación Colombia, 20 I 2. Disponible en http://www.acnur.org/t3/operaciones/situacion-colombia/ (consultado el 27 de Julio de 2013)

ORGANIZACIÓN DE NACIONES UNIDAS, Alto Comissariado das Nações Unidas para os Refugiados - ACNUR, UNHCR Global Report 201 I - Colombia, 20I2, pp. 345-349. Disponible en http://www.unhcr.org/4fc880c0b. html (consultado el I7 de Marzo de 20I4)

ORGANIZACIÓN DE NACIONES UNIDAS, "Alto Comissariado das Nações Unidas para Refugiados ACNUR: Grupo de trabalho do Grupo Setorial Global de Proteção”, Manual para la protección de los desplazados internos, 2010. Disponible en http://www.refworld.org/cgi-bin/texis/vtx/rwmain/opendocpdf. pdf?reldoc=y\&docid=5I54I9462 (consultado el 2 de Mayo de 2013)

ORGANIZACIÓN DE NACIONES UNIDAS, Alto Comissariado das Nações Unidas para os Refugiados - ACNUR, "Working with the internally Displaced" en UNHCR, Global Report 2006, 2007, pp. 40-43. Disponible en http://www.unhcr.org/cgi-bin/texis/vtx/home/opendocPDFViewer.html?docid=4a2fd85b6\&query=Worki ng\%20with\%20the\%20internally\%20Displaced\%202006 (consultado el I 2 de Marzo de 20I4)

ORGANIZACIÓN DE NACIONES UNIDAS, Assembleia Geral Das Nações Unidas - AGNU. World summit outcome, Resolução A/RES/60/I, 24 de Octubre de 2005. Disponible en http://unpan I.un.org/intradoc/groups/ public/documents/un/unpan021752.pdf (consultado el 27 de agosto de 2013)

ORGANIZACIÓN DE NACIONES UNIDAS, “Alto Comissariado das Nações Unidas para os Refugiados - ACNUR, Balance de la política pública de prevención, protección y atención al desplazamiento interno forzado en Colombia (agosto 2002 - agosto 2004), 2004. Disponible en http://www.acnur.org/biblioteca/pdf/2983.pdf?view=I (consultado el 10 de Marzo de 20I4)

ORGANIZACIÓN DE NACIONES UNIDAS, United Nations Office on Drugs and Crime - UNTOC. United Nations Convention Against Transnational Organized Crime and the protocols thereto. Nueva York: United Nations Office on Drugs and Crime. Nova lorque: United Nations, 92p. 2004. Disponible en http://www.unodc. org/documents/treaties/UNTOC/Publications/TOC\%20Convention/TOCebook-e.pdf. (consultado el09 jun. 2012. (consultado el I 3 de Noviembre de 20I3)

ORGANIZACIÓN DE NACIONES UNIDAS, Alto Comissariado das Nações Unidas para os Refugiados - ACNUR, Memorando de intención entre la Oficina del Alto Comisionado de Naciones Unidas para los Refugiados (ACNUR) y el Gobierno de la República de Colombia, relativo al suministro de cooperación para el tratamiento del problema del desplazamiento forzado, 1999. Disponible en http://www.acnur.org/biblioteca/pdf/I530.pdf (consultado el I de Marzo de 2014)

ORGANIZACIÓN DE NACIONES UNIDAS, Alto Comissariado das Nações Unidas para Refugiados - ACNUR. Princípios Orientadores Relativos aos Deslocados Internos - PORDI. 1998. Disponible en http://www.ohchr. org/Documents/Issues/IDPersons/GPPortuguese.pdf (consultado el I 3 de Noviembre de 2013)

ORGANIZACIÓN DE NACIONES UNIDAS, Relatório De Graça Machel no seguimento da Resolução $48 / I 57$ da Assembleia Geral da ONU (Documento A/5I/306, de 28 de agosto de 1996). 1996. Disponible en http:// www.unric.org/html/portuguese/peace/Graca Machel.htm (consultado el I 3 de Noviembre de 2013)

ORGANIZACIÓN DE NACIONES UNIDAS, Conselho Econômico e Social das Nações Unidas - ECOSOC, Commission on Human Rights, "Comprehensive study prepared by Mr. Francis M. Deng, Representative of the Secretary-General on the human rights issues related to internally displaced persons, pursuant to Commission on Human Rights resolution 1992/73" en Further promotion and encouragement of human rights and fundamental freedoms, including the question of the programme and methods of work of the commission, Documento E/CN.4/1993/35, 21 de enero de 1993. Disponible en http://www.unhchr.ch/Huridocda/ Huridoca.nsf/TestFrame/fb36ada4f4e26ce68025672f003ef984 (consultado el I 3 de Noviembre de 20 I3)

ORGANIZACIÓN DE NACIONES UNIDAS, Assembleia Geral das Nações Unidas - AGNU: Convenção relativa ao estatuto dos refugiados (Resolução A/RES/429(V), aprovada em 28 de julho de 195I), I95I. Disponible en http://www.acnur.org/t3/fileadmin/scripts/doc.php?file=t3/fileadmin/Documentos/portugues/BDL/ Convencao relativa ao Estatuto dos Refugiados (consultado el I 3 de Noviembre de 2013)

ORGANIZACIÓN DE NACIONES UNIDĀS, Mid-YearTrends 20/3. Disponible en http://www.unhcr.org/52af08d26. html (consultado el I 3 de Noviembre de 20I3)

PATARRA, Neide Lopes. “Migrações Internacionais: teorias, políticas e movimentos sociais” en Estudos Avançados, vol. 20, n 57, 2006, pp. 7-24.

PÉCAUT, Daniel, As FARC: uma guerrilha sem fins?, Paz e Terra, San Paulo, 2010. 
PEDROSO, Ângela Maria Salvador, "A problemática dos deslocados internos: da natureza dos conflitos armados da actualidade às respostas da comunidade internacional”, Dissertação (Mestrado em Relações Internacionais) - Universidade Técnica de Lisboa, 20II. Disponible en https://www.repository.utl.pt/ handle/I0400.5/3828?mode=full (consultado el I7 de Marzo de 20I4)

PENNAFORTE, Charles, "Colômbia e as Bases Militares dos Estados Unidos" en Revista Geografia, 20I I. Disponible en http://conhecimentopratico.uol.com.br/geografia/fenomenosterrestres/soluções/busca.asp?t=Charles\%20 Pennaforte (consultado el 10 de Enero de 2014)

PHUONG, Catherine, The international protection of internally displaced persons, Cambridge University Press, Cambridge, 2005.

PONTHIEU, Aurélie; DERDERIAN; Katharine, "Respuestas humanitarias en el vacío de protección" en Revista Migraciones Forzadas, $n^{\circ}$ 43, 20I3, pp. 37-40.

POSADA, Paola A.,"Refugiados y desplazados forzados. Categorías de la migración forzada creadas como medidas de contención a las migraciones no deseadas" en Estudios Políticos, n³5, 2009, pp. I3 I-I52.

RICO, Daniel M., "Las Dimensiones Internacionales del Crime Organizado en Colombia: Las Bacrim, sus Rutas y Refugios" en GARZÓN, Juan Carlos; OLSON, Eric L. (orgs.), La diáspora criminal: la difusión transnacional del crimen organizado y cómo contener su expansión, Woodrow Wilson International Center for Scholars, Pennsylvania, 2013, pp. 27-57.

RÍOS, Sierra, Jerónimo, Breve historia del conflicto armado en Colombia, Los Libros de la Catarata, Madrid, 20I7, pp. I I 0112.

RIVAS NIETO, Pedro; GARCÍA, Pablo Rey, Las autodefensas y el paramilitarismo en Colombia (1964-2006), Confines de Relaciones Internacionales y Ciencia Política, Monterrey, 2008.

RIVERA, “Edgar de Jesús Velásquez. Historia del paramilitarismo en Colombia” en História, vol. 26, n I, 2007, pp. I34153.

ROJAS, Diana Marcela, “Estados Unidos e la Guerra en Colombia” en GUTIÉRREZ, Francisco;WILLIS, María Emma; GÓMEZ, Gonzalo, Sánchez (orgs.), Nuestra guerra sin nombre:transformaciones del conflicto en Colombia, Grupo Editorial Norma, Bogotá, 2005, pp. 39-69.

ROMERO, Marco Alberto, “Desplazamiento forzado: entre la guerra y la economía política del despojo”, Universidad Nacional de Colombia y CODHES, Bogotá, 2007.

ROMERO, Marco Alberto, "El año de los derechos de las personas desplazadas en Colombia" en Revista Migraciones Forzadas, $n^{\circ} 29,2008$

ROSENAU, James Nathan, "Governança, ordem e transformação na política mundial” en BATH, Sérgio; ROSENAU, James Nathan; CZEMPIEL, Ernest-Otto, Governança sem governo: ordem e transformação na política mundial, Imprensa Oficial do Estado, San Paulo, 2000, pp. I I-46.

RUGGIE, John Gerard, “Multilateralism: the Anatomy of an Institution” en International Organization, Cambridge, vol 46, n 3, 1992, pp. 56I-598.

SANTOS, Marcelo, “O conflito colombiano e o Plano Colômbia” en UFRR (Coleção Relações Internacionais), vol. 3, 201 I . SMOUTS, Marie-Claude (org.), As novas relações internacionais: práticas e teorias, UNB, Brasilia, 2004.

STOBBAERTS, Eric; MARTIN, Sarah; DERDERIAN, Katharine, "Integración y reforma humanitarian" en Revista Migraciones Forzadas, $\mathrm{n}^{\circ}$ 29, 2008, pp. 18-20.

TAUBURET-KELLER,André,“Questões relacionadas a uma psicologia clínica do bilingüismo” en VERMES, G.; BOUTET, J (orgs.), Multilinguísmo, UNICAMP, Campinas, I989, pp. 247-26I.

TIMO, Pétalla Brandão, "Quando o doméstico é internacional: a problemática do deslocamento interno de pessoas" en Revista Cadernos de Relações Internacionais, vol. 2, n², 2009.

UNIDAD PARA LA ATENCIÓN Y REPARACIÓN INTEGRAL A LAS VÍCTIMAS, Protección de Tierras y Patrimonio de la Población Desplazada, 2013. Disponible en http://dpp.gov.co/contenido/contenido. aspx?cat|D=295\&conID=334I (consultado el 25 de Febrero de 20I4)

VIANA, Manuela Trindade, "Cooperação internacional e deslocamento interno na Colômbia: desafios à maior crise humanitária da América do Sul” en Revista Internacional de Direitos Humanos - SUR, San Paulo, vol. 6, $\mathrm{n}^{\circ}$ I0, 2009, pp. I38-I6I.

WEISS, Thomas; KORN, David, Internal displacement: conceptualisations and its consequences, Routlege, Londres, 2006.

ZUBIRIA, S., "Comisión Histórica del Conflicto y sus Víctimas”, Reporte: Contribuición AL entedimiento del conflicto armado en Colombia, Imprenta Nacional, Bogotá, 2015. 


\section{RELACIONES INTERNACIONALES}

Revista académica cuatrimestral de publicación electrónica Grupo de Estudios de Relaciones Internacionales (GERI)

Universidad Autónoma de Madrid, España

https://revistas.uam.es/relacionesinternacionales

ISSN 1699 - 3950

f facebook.com/RelacionesInternacionales

3. twitter.com/RRInternacional 